Chapman University

Chapman University Digital Commons

$11-26-2017$

\title{
Combinational siRNA Delivery Using Hyaluronic Acid Modified Amphiphilic Polyplexes Against Cell Cycle and Phosphatase Proteins to Inhibit Growth and Migration of Triple-Negative Breast Cancer Cells
}

Manoj B. Parmar

Daniel Nisakar Meenakshi Sundaram

Remant Bahadur KC

Robert Maranchuk

Hamidreza Montazeri Aliabadi

See next page for additional authors

Follow this and additional works at: http://digitalcommons.chapman.edu/pharmacy_articles

Part of the Amino Acids, Peptides, and Proteins Commons, Cancer Biology Commons, Medical Genetics Commons, Oncology Commons, and the Women's Health Commons 


\section{Combinational siRNA Delivery Using Hyaluronic Acid Modified Amphiphilic Polyplexes Against Cell Cycle and Phosphatase Proteins to Inhibit Growth and Migration of Triple-Negative Breast Cancer Cells}

Comments

NOTICE: this is the author's version of a work that was accepted for publication in Acta Biomaterialia. Changes resulting from the publishing process, such as peer review, editing, corrections, structural formatting, and other quality control mechanisms may not be reflected in this document. Changes may have been made to this work since it was submitted for publication. A definitive version will be subsequently published in Acta Biomaterialia in 2017. DOI:10.1016/j.actbio.2017.11.036

The Creative Commons license below applies only to this version of the article.

\section{Creative Commons License}

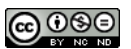

This work is licensed under a Creative Commons Attribution-Noncommercial-No Derivative Works 4.0 License.

\section{Copyright}

Elsevier

\section{Authors}

Manoj B. Parmar, Daniel Nisakar Meenakshi Sundaram, Remant Bahadur KC, Robert Maranchuk, Hamidreza Montazeri Aliabadi, Judith C. Hugh, Raimar Löbenberg, and Hasan Uludağ 


\section{Accepted Manuscript}

Full length article

Combinational siRNA delivery using hyaluronic acid modified amphiphilic polyplexes against cell cycle and phosphatase proteins to inhibit growth and migration of triple-negative breast cancer cells

Manoj B. Parmar, Daniel Nisakar Meenakshi Sundaram, KC. Remant Bahadur, Robert Maranchuk, Hamidreza Montazeri Aliabadi, Judith C. Hugh, Raimar Löbenberg, Hasan Uludă

PII:

S1742-7061(17)30720-1

DOI:

Reference: https://doi.org/10.1016/j.actbio.2017.11.036

ACTBIO 5189

To appear in:

Acta Biomaterialia

Received Date: $\quad 18$ July 2017

Revised Date: $\quad 5$ November 2017

Accepted Date: $\quad 21$ November 2017

Please cite this article as: Parmar, M.B., Sundaram, D.N.M., Bahadur, C.R., Maranchuk, R., Aliabadi, H.M., Hugh, J.C., Löbenberg, R., Uludağ, H., Combinational siRNA delivery using hyaluronic acid modified amphiphilic polyplexes against cell cycle and phosphatase proteins to inhibit growth and migration of triple-negative breast cancer cells, Acta Biomaterialia (2017), doi: https://doi.org/10.1016/j.actbio.2017.11.036

This is a PDF file of an unedited manuscript that has been accepted for publication. As a service to our customers we are providing this early version of the manuscript. The manuscript will undergo copyediting, typesetting, and review of the resulting proof before it is published in its final form. Please note that during the production process errors may be discovered which could affect the content, and all legal disclaimers that apply to the journal pertain. 


\section{Combinational siRNA delivery using hyaluronic acid modified}

\section{amphiphilic polyplexes against cell cycle and phosphatase}

\section{proteins to inhibit growth and migration of triple-negative}

\section{breast cancer cells}

Manoj B. Parmar ${ }^{\mathrm{a}}$, Daniel Nisakar Meenakshi Sundaram ${ }^{\mathrm{a}}$, Remant Bahadur KC ${ }^{\mathrm{b}}$, Robert Maranchuk ${ }^{\mathrm{c}}$, Hamidreza Montazeri Aliabadi ${ }^{\mathrm{d}}$, Judith C. Hugh ${ }^{\mathrm{e}}$, Raimar Löbenberg ${ }^{\mathrm{a}}$, Hasan Uludağ ${ }^{\mathrm{a}, \mathrm{b}, \mathrm{f}^{*}}$

${ }^{a}$ Faculty of Pharmacy \& Pharmaceutical Sciences, U. of Alberta, Edmonton, AB, Canada

${ }^{\mathrm{b}}$ Department of Chemical \& Materials Engineering, Faculty of Engineering, U. of Alberta, Edmonton, $\mathrm{AB}$, Canada

${ }^{c}$ Department of Medical Microbiology and Immunology, Faculty of Medicine and Dentistry, U. of Alberta, Edmonton, AB, Canada

${ }^{\mathrm{d}}$ School of Pharmacy, Chapman University, Irvine, California, USA

${ }^{\mathrm{e}}$ Department of Laboratory Medicine \& Pathology, U. of Alberta, Edmonton, AB, Canada

${ }^{\mathrm{f}}$ Department of Biomedical Engineering, Faculty of Medicine \& Dentistry, U. of Alberta, Edmonton, $\mathrm{AB}$, Canada

*Correspondence: Prof. Hasan Uludağ, 2-021 RTF, Department of Chemical \& Materials Engineering, Faculty of Engineering, U. of Alberta, Edmonton AB T6G 2V2, Canada. E-mail: huludag@ualberta.ca 


\begin{abstract}
Triple-negative breast cancer is an aggressive form of breast cancer with few therapeutic options if it recurs after adjuvant chemotherapy. RNA interference could be an alternative therapy for metastatic breast cancer, where small interfering RNA (siRNA) can silence the expression of aberrant genes critical for growth and migration of malignant cells. Here, we formulated a siRNA delivery system using lipid-substituted polyethylenimine (PEI) and hyaluronic acid (HA), and characterized the size, $\zeta$-potential and cellular uptake of the nanoparticulate delivery system. Higher cellular uptake of siRNA by the tailored PEI/HA formulation suggested better interaction of complexes with breast cancer cells due to improved physicochemical characteristics of carrier and HA-binding CD44 receptors. The siRNAs against specific phosphatases that inhibited migration of MDA-MB-231 cells were then identified using library screen against 267 protein-tyrosine phosphatases and siRNAs to inhibit cell migration were further validated. We then assessed the combinational delivery of a siRNA against CDC20 to decrease cell growth and a siRNA against several phosphatases shown to decrease migration of breast cancer cells. Combinational siRNA therapy against CDC20 and identified phosphatases PPP1R7, PTPN1, PTPN22, LHPP, PPP1R12A and DUPD1 successfully inhibited cell growth and migration, respectively, without interfering with the functional effect of the co-delivered siRNA. The identified phosphatases could serve as potential targets to inhibit migration of highly aggressive metastatic breast cancer cells. Combinational siRNA delivery against cell cycle and phosphatases could be a promising strategy to inhibit both growth and migration of metastatic breast cancer cells, and potentially other types of metastatic cancer.
\end{abstract}

\title{
Key words:
}

Amphiphilic polymers, siRNA delivery, breast cancer therapy, cell cycle protein, phosphatase protein 


\section{Introduction}

Despite advances in the diagnosis and treatment of breast cancer, the metastasis of breast cancer to distant organs continues to be the major cause of death [1,2]. Having spread to the rest of the body, metastatic breast cancer can only be addressed by systemic chemotherapies that have many toxic side effects due to the non-specificity of their action. Targeted agents developed to block estrogen receptor, progesterone receptor or human epidermal growth factor receptor 2 (HER2), are only of use in tumors that display the corresponding receptors [3]. However, a common sub-type of breast cancer, triplenegative breast cancer, lacks these three receptors and are not candidates for existing targeted therapies because of the lack of utility when the targeted receptors are absent. Triple-negative breast cancer affects $12-17 \%$ of patients, and although it initially responds well to primary chemotherapy, has a high recurrence rate with poor survival [4,5]. RNA interference (RNAi) is a relatively recent targeted therapy that is ideal for triple-negative breast cancer cells since it can address aberrant factors specifically associated with these cells. The synthetic pharmacological RNAi agent, small-interfering RNA (siRNA), can target specific mRNA, silencing the expression of the corresponding protein [6]. Once siRNA is introduced to the cell, it incorporates into the RNA inducing silencing complex (RISC) followed by degradation of the passenger strand of double-stranded siRNA. The other "guide" strand of siRNA then guides the RISC assembly to its targeted mRNA that is directing the translation of the corresponding protein. The RISC assembly loaded with the guide strand of siRNA cleaves the mRNA or inhibit the translation, leading to the silencing of that protein in the cell [7].

However, siRNA is a highly labile, anionic and nuclease-sensitive molecule, and needs a carrier that can transport it to the cell and protect it from extracellular degradation [8]. To facilitate the entry of siRNA into the cell, we have previously developed a library of cationic polymeric carriers that are based on low molecular weight polyethylenimines (PEI) $[9,10]$. High molecular weight PEIs possess 
excess cationic charge that readily disrupts the plasma membrane, leading to significant toxicity of the carrier itself. In contrast, minimal toxicity has been reported for low molecular weight $(<2.0 \mathrm{kDa})$ PEIs, making them more suitable for the delivery of siRNA. We have shown that modification of these PEIs with lipidic moieties results in efficient uptake of siRNA/PEI complexes $[10,11]$, presumably due to improved chemical compatibility of siRNA/PEI complexes with cell membrane as a result of introduced hydrophobic moieties.

In this study, we introduce hyaluronic acid (HA) to siRNA/PEI complexes and show a drastic increase in cellular uptake. HA is an anionic, nonsulfated glycosaminoglycan distributed widely throughout connective, epithelial, and neural tissues. It is one of the main component of extracellular matrix, and is known to contribute to cell proliferation [12]. In 1990, Aruffo et al. identified HA as the primary binding molecule of cluster of differentiation-44 (CD44), a cell-surface glycoprotein that plays a significant role in a number of biological functions, including cell-cell interactions, cell adhesion and migration [13]. Since the CD44 receptor is over-expressed in a variety of solid tumors, and is known to be increased in triple negative breast cancers [14,15], the HA formulated delivery system can potentially bind to over-expressed CD44 receptors selectively, increasing the uptake of siRNA in cancer cells. Thus, the HA-formulated delivery agent could assist in the discrimination between healthy and malignant cells in vivo with a reduction of off-target toxicity.

One of the hallmarks of cancer is the deregulation of the cell cycle due to up-regulation of many essential proteins that control cell division [16]. Targeting and silencing these up-regulated cell cycle proteins could lead to inhibition of cell proliferation, and decrease the growth of cancer cells. One of the cell cycle proteins we identified previously, based on a library screen of siRNAs targeting proteins involved in cell cycle regulation, is cell-division cycle protein 20 (CDC20) [17]. CDC20 activates the anaphase-promoting complex (APC) in the cell cycle during mitosis, which initiates chromatid separation and entrance of the cell division into anaphase [18]. Since CDC20 plays a key role during 
mitosis, silencing its expression by siRNA could potentially lead to cell cycle arrest, thereby decreasing tumor cell growth.

Since down-regulating a single target involved in cell growth may be ineffective in metastatic cancer, we pursued combinational therapy inhibiting both cell growth as well as migration as a more effective strategy. Several reports have suggested involvement of protein-tyrosine phosphatases in the metastasis of several types of cancer [19-22]. Protein-tyrosine phosphatases function in signal transduction by deactivating kinases with the removal of phosphate group from phosphorylated tyrosine. The de-regulation or over-expression of protein-tyrosine phosphatases is evident in many types of cancers including breast cancer [23-25]. Therefore, we investigated whether silencing phosphatases with siRNA could decrease cellular migration and ultimately contribute to a useful therapeutic development for triple-negative breast cancer.

In this report, we tested the hypothesis that dual siRNA therapy against a cell cycle protein (to decrease cell growth) and a phosphatase (to decrease metastasis) may have a more drastic impact on the growth of triple-negative breast cancers. We first synthesized lipid-substituted low molecular weight PEI followed by a formulation of PEI/HA for the delivery of siRNA. We then characterized the PEI/HA delivery carrier and determined its efficiency at delivering siRNA by cellular uptake and cell growth inhibition. We also determined a potential role of CD44 surface receptor for the uptake of siRNA when siRNA was delivered with PEI/HA. We additionally screened a library of siRNAs against 267 phosphatase targets to identify potential candidates to reduce the migration of tripe-negative breast cancer cells followed by a combinational siRNA therapy targeting cell cycle (CDC20) and identified phosphatase proteins to decrease cell growth as well as migration simultaneously.

\section{Materials and Methods}

\subsection{Materials}


The amines of low molecular weight PEI (1.2 kDa) were substituted with linoleic acid via Nacylation (PEI-LA) and the degree of substitution on the polymer (PEI-LA) was determined by ${ }^{1} \mathrm{H}$ NMR spectroscopy, as previously described [26,27]. HA ( 300 kDa), doxorubicin, MTT [3-(4 5dimethylthiazol-2-yl)-2 5-diphenyltetrazolium] and dimethyl sulfoxide (DMSO) were purchased from Sigma-Aldrich (St. Louis, MO). Hank's Balanced Salt Solution (HBSS) was prepared in-house.

Silencer® Human Phosphatase siRNA Library V3 (Cat. No. AM80140v3) containing siRNAs against 267 phosphatases was purchased from Ambion (Foster City, CA). All siRNAs against CD44 (Cat. No. HSC.RNAi.N000610.12.1), CDC20 (Cat. No. HSC.RNAi.N001255.12.1), protein phosphatase 1 regulatory subunit 7 (PPP1R7, Cat. No. HSC.RNAI.N002712.12.1), protein tyrosine phosphatase, non-receptor type 1 (PTPN1, Cat. No. HSC.RNAI.N002827.12.1), protein tyrosine phosphatase, non-receptor type 22 (PTPN22, Cat. No. HSC.RNAI.N015967.12.1), phospholysine phosphohistidine inorganic pyrophosphate phosphatase (LHPP, Cat. No. HSC.RNAI.N022126.12.1), protein phosphatase 1 regulatory subunit 12A (PPP1R12A, Cat. No. HSC.RNAI.N002480.12.1), dual specificity phosphatase and pro isomerase domain containing 1 (DUPD1, Cat. No. HSC.RNAI.N001003892.12.1), and negative control scrambled siRNA (Cat. No. DS NC1) were ordered from IDT (Coralville, IA). The 6-Carboxyfluorescein (FAM) labeled scrambled siRNA was purchased from IDT. Primers for CD44 (forward: GCTTCAATGCTTCAGCTCCAC; reverse: TTTCTGGACATAGCGGGTGC), CDC20 (forward: CGCTATATCCCCCATCGCAG; reverse: GATGTTCCTTCTTGGTGGGC), PPP1R7 (forward: GAAAGGGGAAGAGCAGCCAA; reverse: CGCCTGTCAACCTCCATCA), PTPN1 (forward: AGAGACGTCAGTCCCTTTGAC; reverse: ACTCCTTTGGGCTTCTTCCATT), PTPN22 (forward: GGGAAAGAAAAAGTGTGAGCG; reverse: CACAGGATACAGAGAAAGGGC), LHPP (forward: CCGTCATGATTGGGGACGA; reverse: CTCGTCACTGGGCCTGAAC), PPP1R12A (forward: CAACAAAGTGGGCCAAACAG; reverse: CCCGTTTTTCACTATGGAGCAG), DUPD1 (forward: AAGCGACGACCACAGTAAGA; reverse: GTGGATCATCAGGTAGGCCAG), and Glyceraldehyde 3-phosphate dehydrogenase (GAPDH; 
forward: TCACTGTTCTCTCCCTCCGC; reverse: TACGACCAAATCCGTTGACTCC) were supplied by IDT. PE Mouse Anti-Human CD44 (Clone 515) and PE Mouse Anti-Human IgG (Clone G18-145) antibodies were purchased from BD Pharmingen (Franklin Lakes, NJ).

\subsection{Cell culture}

The triple-negative breast cancer MDA-MB-231 cells were cultured in DMEM medium with $10 \%$ fetal bovine serum (FBS), $100 \mathrm{U} / \mathrm{mL}$ penicillin and $100 \mu \mathrm{g} / \mathrm{mL}$ streptomycin. Another triplenegative breast cancer SUM149PT cells, and estrogen/progesterone-positive MCF7 cells were cultured in DMEM/F12 medium with $10 \%$ fetal bovine serum (FBS), $100 \mathrm{U} / \mathrm{mL}$ penicillin and $100 \mu \mathrm{g} / \mathrm{mL}$ streptomycin. All cells were maintained in a humidified atmosphere at $37{ }^{\circ} \mathrm{C}$ and $95 / 5 \%$ air/ $\mathrm{CO}_{2}$. MDA-MB-231 and MCF7 cells were a generous gift from Dr. Judith Hugh, Department of Laboratory Medicine \& Pathology, University of Alberta, while SUM149PT cells was a gift from Dr. Afsaneh Lavasanifar, Faculty of Pharmacy and Pharmaceutical Sciences, University of Alberta. All cells were authenticated by STR DNA profiling analysis.

\subsection{Preparation of siRNA/polymer complexes}

The siRNA/polymer complexes were prepared in two different ways (Fig 1): 1) HA Additive: HA was first added to siRNA at pre-specified concentrations followed by addition of the required volume of $150 \mathrm{mM} \mathrm{NaCl}$. PEI-LA was then added to the siRNA/HA solution to allow a final complexation process for $30 \mathrm{~min}$. 2) HA Coating: the siRNA/PEI-LA complexes in $150 \mathrm{mM} \mathrm{NaCl}$ were prepared first by adding PEI-LA to siRNA with 30 min of incubation. Once siRNA/PEI-LA complexes were formed, HA was added to coat the complexes for $30 \mathrm{~min}$.

\subsection{Size and $\zeta$-potential of siRNA/polymer complexes}


To characterize the siRNA/polymer complexes based on different amounts of HA in the complexation process, the hydrodynamic diameter (Z-average) and surface charge ( $\zeta$-potential) of these complexes were determined in $\mathrm{ddH}_{2} \mathrm{O}$ through dynamic light scattering (DLS) and electrophoretic light scattering (ELS) using Zetasizer Nano ZS (Malvern, UK), respectively. The complexes were prepared as described above with HA additive and coating using $0.6 \mu \mathrm{g}$ of scrambled siRNA at 1:6 siRNA:PEILA w/w ratio, and 1:0, 1:0.05, 1:0.5, 1:1, 1:4 and 1:8 siRNA:HA w/w ratios. The complexes were diluted to $1 \mathrm{~mL} \mathrm{ddH}_{2} \mathrm{O}$ before each measurement.

\section{5. siRNA uptake by flow cytometry and confocal microscopy}

To determine siRNA delivery efficiency of complexes made with different amounts of HA, MDA-MB-231 cells were transfected with FAM-labeled siRNA at 40 nM with 1:6 siRNA:PEI-LA w/w ratio, and 1:0, 1:0.05, 1:0.5, 1:1, 1:4 and 1:8 siRNA:HA w/w ratios. As a negative control, non-labeled scrambled siRNA was used to make complexes at 1:6:1 siRNA:PEI-LA:HA w/w/w ratio. Cells were treated with complexes prepared as HA additive and coating, and were trypsinized after 24 hrs of siRNA transfection. Cell were fixed with $3.7 \%$ formaldehyde after washing with HBSS. The uptake of siRNA was quantified using BD LSRFortessa ${ }^{\mathrm{TM}}$ cell analyzer (Becton Dickinson, Franklin Lakes, NJ). The mean fluorescence of the recovered cell population and the percentage of cells showing FAMfluorescence were determined after gating of the cell population as such that auto-fluorescence of nontreated cells represented $\sim 1 \%$ of the total cell population.

To further investigate qualitative uptake of siRNA, MDA-MB-231 were grown on glass cover slips (Thermo Fisher Scientific) for $24 \mathrm{hrs}$ and transfected by FAM-labeled scrambled siRNA complexes at $40 \mathrm{nM}$ with 1:6:0, 1:6:0.05, 1:6:1 and 1:6:8 siRNA:PEI-LA:HA w/w/w ratios. As a negative control, non-labeled scrambled siRNA was used to make complexes at 1:6:1 siRNA:PEILA:HA w/w/w ratio. After 24 hrs, cells were washed with HBSS, fixed with $4 \%$ paraformaldehyde for $20 \mathrm{~min}$ at $37^{\circ} \mathrm{C}$ and mounted on a slide using in-house prepared mounting medium (poly vinyl alcohol 
in glycerol) with 4',6-diamidino-2-phenylindole (DAPI, Life Technologies) to stain nuclei and wheat germ agglutinin, Texas Red conjugate (Invitrogen) to stain the cytoplasmic membrane. Prepared slides were studied using 40x 1.3 oil plan-Apochromat lens in a Laser Scanning Confocal Microscope (LSM710, Carl Zeiss AG, Oberkochen, Germany), and using ZEN 2011 software.

To determine the retention period of siRNA in the cell, a time-course study was performed using confocal microscopy. MDA-MB-231 cells were transfected by FAM-labeled scrambled siRNA at $40 \mathrm{nM}$ with 1:6:0 and 1:6:1 siRNA:PEI-LA:HA w/w/w ratios, and slides for confocal microscopy were prepared as mentioned above after 4, 24, 48 and $72 \mathrm{hrs}$ of transfection. The number of siRNA-polymer complexes per cell was determined by Imaris software (Bitplane, Belfast, UK).

\section{6. siRNA uptake after CD44 silencing}

To determine the role of CD44 in the uptake of HA-formulated complexes, MDA-MB-231 was transfected with 60 nM CD44 siRNA at 1:6:1 siRNA:PEI-LA:HA w/w/w ratio. After 72 hrs, cells were exposed to FAM-labeled siRNA with $40 \mathrm{nM}$ at 1:6:0 and 1:6:1 siRNA:PEI-LA:HA w/w/w ratio prepared as HA additive and coated complexes. The uptake of FAM-labeled siRNA was determined as described above using a BD Accuri ${ }^{\mathrm{TM}}$ C6 Plus Flow Cytometer (BD Biosciences, Franklin Lakes, NJ) after 4 hrs.

To determine the silencing efficiency of CD44 siRNA at the protein level, MDA-MB-231 cells were transfected with $60 \mathrm{nM}$ CD44 siRNA at 1:6:0 and 1:6:1 siRNA:PEI-LA:HA w/w/w ratios. After 72 hrs, cells were washed with HBSS and incubated with PE-labeled anti-human control IgG and antihuman CD44 antibodies for $1 \mathrm{hr}$ at room temperature. Cells were trypsinized and fixed with 3.7\% formaldehyde. The surface binding of control IgG and CD44 antibodies were then quantified using BD Accuri ${ }^{\mathrm{TM}}$ C6 Plus Flow Cytometer (BD Biosciences).

The silencing efficiency of CD44 specific siRNA at the transcript level was determined by the Reverse Transcription - quantitative PCR (RT-qPCR). MDA-MB-231 cells were transfected with 60 
nM CD44 siRNA at 1:6:0 and 1:6:1 siRNA:PEI-LA:HA w/w/w ratios. After 48 hrs, RT-qPCR was performed as described in RT-qPCR section below (Section 2.11).

\subsection{Comparison of CD44 levels and siRNA uptake among MDA-MB-231, SUM149PT and MCF7 cells}

CD44 surface protein and transcripts levels in the cells were determined by immunostaining and RT-qPCR, respectively. MDA-MB-231, SUM149PT and MCF7 cells were stained with PE-labeled anti-human control IgG and anti-human CD44 antibodies for $1 \mathrm{hr}$ at room temperature, and surface binding of antibodies were then quantified as described above (Section 2.6). To determine the levels of CD44 transcripts, total mRNA was isolated from MDA-MB-231, SUM149PT and MCF7 cells, and RT-qPCR was performed as described in section below (Section 2.11).

To compare the relative uptake of siRNA by MDA-MB-231 to other cell types, SUM149PT and MCF7 cells were treated with $40 \mathrm{nM}$ FAM-labeled siRNA at 1:6:0 and 1:6:1 siRNA:PEI-LA:HA w/w/w ratio prepared as HA additive and coated complexes. After $24 \mathrm{hrs}$ of siRNA treatment, the uptake of FAM-labeled siRNA was determined as described above using a BD Accuri ${ }^{\text {TM }}$ C6 Plus Flow Cytometer (BD Biosciences).

\subsection{Functional evaluation of different siRNA:HA ratios in siRNA/polymer complexes}

Various amounts of HA ranging from 1:0 to 1:12 siRNA:HA w/w ratio was used to make HA additive and coating complexes at $20 \mathrm{nM}$ siRNA with 1:6 siRNA:PEI-LA w/w ratio. Scrambled siRNA was used as a negative control. To evaluate a functional efficacy of siRNA/polymer complexes, MDAMB-231 cells were treated with CDC20 siRNA and the inhibition of cell growth was determined by MTT assay. The complexes were prepared as described above for HA additive and coating and added to cells. After $72 \mathrm{hrs}$ of treatment, MTT was added to the cells at $1 \mathrm{mg} / \mathrm{mL}$ final concentration in HBSS. The cells were incubated for $1 \mathrm{hr}$ at $37^{\circ} \mathrm{C}$ and $5 \% \mathrm{CO}_{2}$. During this incubation, soluble MTT is 
transformed into insoluble formazan crystals due to the activity of mitochondrial dehydrogenase enzymes, giving a measure of cellular activity [28]. DMSO was added to the well to dissolve the formazan crystals formed because of cellular activity of live cells. The optical density (OD) was measured at $570 \mathrm{~nm}$ and the ODs were summarized as a percentage of cell growth based on non-treated cells (taken as $100 \%$ cell growth).

\subsection{Screening of phosphatase proteins}

Silencer® Human Phosphatase siRNA Library V3 (Ambion) was used to screen 267 phosphatase proteins to determine the potential phosphatase proteins that can decrease the migration of metastatic breast cancer cells. The siRNAs against each phosphatase was a pool of three siRNAs targeting different locations of the phosphatase mRNA. To assess the efficacy of phosphatase siRNAs, MDA-MB-231 cells were cultured in 96-well plate and transfected with $40 \mathrm{nM}$ of each phosphatase siRNA at 1:6 siRNA:PEI-LA w/w ratio without HA. After $72 \mathrm{hrs}$ of siRNA treatment, inhibition of cell growth was assessed by MTT assay as described above.

To identify potential phosphatase targets that could reduce the migration of MDA-MB-231 cells, a scratch assay [29] was performed for the entire library of phosphatase proteins. Cells were cultured in 96-well plates and transfected with $40 \mathrm{nM}$ of each phosphatase siRNA at 1:6 siRNA:PEILA w/w ratio without HA. After 48 hrs of siRNA treatment, a scratch was made in each well using P200 pipette tips. The cells were allowed to migrate for $24 \mathrm{hrs}$, and were then stained by coomassie brilliant blue R-250 (Thermo Fisher Scientific). The plates were scanned and grayscale values for each well was determined by ImageJ software [30]. CDC20 siRNA was also used as a control in the library screen, while doxorubicin $(5 \mu \mathrm{g} / \mathrm{ml})$ was used as a positive control as it can not only decrease the growth of breast cancer cells, but also inhibit migration of cells. The migration of cells and percent of control for the migrated cells was calculated as follows: 
Migration of cells $=\frac{(\mathrm{A} 0-\mathrm{A})}{(\mathrm{A} 0-\mathrm{A} \infty)}$

Where, $\mathrm{A}_{0}$ : Grayscale value at $0 \mathrm{hr}$

A : Grayscale value after $24 \mathrm{hr}$ of migration

$\mathrm{A}_{\infty}$ : Grayscale value of non-migrated cells in a well

Percent of Control $(\boldsymbol{P O C})=\frac{\text { Migration of cells }(\text { Phosphatase siRNA })}{\text { Migration of cells }(\text { Control siRNA })} \%$

\subsection{Validation of identified targets}

The potential phosphatase targets were identified based on an initial screen of siRNAs against phosphatase proteins. For validation, individual siRNAs against these phosphatase proteins were obtained from IDT, and MTT and scratch assays were performed to determine the inhibition of MDAMB-231 cell growth and migration, respectively. The siRNAs against CDC20, PPP1R7, PTPN1, PTPN22, LHPP, PPP1R12A and DUPD1 were delivered to MDA-MB-231 cells at 20, 40 and $60 \mathrm{nM}$ concentrations with 1:3 and 1:6 siRNA:PEI-LA w/w ratios. Scrambled siRNA and doxorubicin (2 $\mu \mathrm{g} / \mathrm{ml}$ ) were also used in the validation study as negative and positive controls, respectively. To determine the migration of cell, scratch was made in each well using P-200 pipette tips after 48 hrs of siRNA treatment and a picture of each well was taken by FSX100 Microscope (Olympus, Tokyo, Japan), which was considered as $0 \mathrm{hr}$ migration. The cells were allowed to migrate for $24 \mathrm{hrs,}$ and pictures of each well were taken again. The migration of cells in each of the $0 \mathrm{hr}$ and $24 \mathrm{hr}$ pictures was calculated by determining the scratch area by TScratch software [31]. The migration of cells and percent of control for the migrated cells was calculated as follows:

$$
\begin{aligned}
& \text { Migration of cells }=\frac{(\text { Migration at } 0 \mathrm{hr})}{(\text { Migration at } 0 \mathrm{hr}-\text { Migration at } 24 \mathrm{hrs})} \\
& \text { Percent of Control }(\text { POC })=\frac{\text { Migration of cells (Phosphatase siRNA) }}{\text { Migration of cells (Control siRNA) }} \%
\end{aligned}
$$




\subsection{Transwell migration assay}

MDA-MB-231 cells were cultured on 6-well plates, $24 \mathrm{hrs}$ prior to the siRNA treatment. The siRNA/PEI-LA complexes at $40 \mathrm{nM}$ siRNA with 1:6 ratio without HA were then added to the cells and incubated at $37{ }^{\circ} \mathrm{C}$ for $48 \mathrm{hrs}$. The cells were then washed gently with HBSS to remove the serum content and trypsinized. Cells were resuspended in serum-free medium and $1.5 \times 10^{5}$ cells were added to transwell inserts. The lower chamber of the wells containing the inserts was filled with medium containing $20 \%$ serum as a chemoattractant. Scrambled siRNA-treated cells were added to the inserts that contained serum as well as serum-free media in the lower bottom well, which served as negative and positive controls, respectively. Doxorubicin-treated cells $(5 \mu \mathrm{g} / \mathrm{ml})$ were also used in this study as a therapeutic positive control. Cells were allowed to migrate from the upper chamber to the bottom surface of the insert for $24 \mathrm{hrs}$. Cells present on the upper surface of the inserts (non-migrated cells) were removed gently using a cotton swab. The inserts were then fixed with $3.7 \%$ formaldehyde for 20 min and stained with $0.1 \%$ crystal violet for $1 \mathrm{~h}$. The inserts were washed with HBSS before imaging under FSX100 Microscope (Olympus). The dye was subsequently solubilized with 10\% acetic acid, and the optical density (OD) was measured at $570 \mathrm{~nm}$ using the $\mathrm{EL}_{\mathrm{x}} 800$ Universal Microplate reader (Bio-Tek Instruments, Winooski, VT). The ODs were summarized as a percentage of cell migration based on non-treated cells with serum in the lower bottom well (taken as 100\% cell migration).

\subsection{Reverse transcription - quantitative PCR (RT-qPCR)}

MDA-MB-231 cells were transfected by combinational CDC20/phosphatase siRNAs at total 40 $\mathrm{nM}(20 \mathrm{nM}$ CDC20 siRNA $+20 \mathrm{nM}$ phosphatase siRNA) as well as individual CDC20 and phosphatase siRNAs (20 nM individual siRNA + $20 \mathrm{nM}$ scrambled siRNA) with 1:6:1 siRNA:PEILA:HA w/w/w ratio. After 24 hrs of siRNA treatment, total RNA was isolated from cells using TRIzol reagent (Invitrogen, Carlsbad, CA). One microgram of total RNA was converted into cDNA using MMLV reverse transcriptase (Invitrogen) according to manufacturer's instruction. StepOne Real-Time 
PCR System (Applied Biosystems, Foster City, CA) was employed to perform quantitative PCR (qPCR) with $15 \mathrm{ng}$ of cDNA from each sample and a SYBR Green qPCR Mastermix (Molecular Biology Service Unit, Department of Biological Sciences, University of Alberta, Edmonton, AB) based on the manufacturer recommendations. Primers were designed using NCBI Primer-BLAST (http://www.ncbi.nlm.nih.gov/tools/primer-blast/). GAPDH was used as a reference gene in RT-qPCR and template cDNA was omitted from qPCR reaction as a negative control. The qPCR results were analyzed using $2^{-\Delta \Delta C}$ method and presented as relative quantity of transcripts [32]. The qPCR conditions comprised an initial denaturation step for $10 \mathrm{~min}$ at $95.0^{\circ} \mathrm{C}$, followed by 40 cycles at 95.0 ${ }^{\circ} \mathrm{C}$ for $15 \mathrm{~s}$ (denaturation), and annealing and elongation at $60{ }^{\circ} \mathrm{C}$ for $1 \mathrm{~min}$.

\subsection{Combinational siRNA therapy}

Combinational siRNA delivery was performed in MDA-MB-231 using CDC20 and phosphatase siRNAs at total $40 \mathrm{nM}(20 \mathrm{nM}$ each) siRNA concentration with 1:3:1 and 1:6:1 siRNA:PEI-LA:HA w/w/w ratios. Individual CDC20 or phosphatase siRNA at total $40 \mathrm{nM}$ concentration (20 nM individual siRNA + $20 \mathrm{nM}$ scrambled siRNA) with 1:3:1 and 1:6:1 siRNA:PEILA:HA w/w/w ratios was delivered in MDA-MB-231 cells as well. To determine the efficacy of combinational siRNA therapy to inhibit cell growth and migration, MTT and scratch assays were performed as described above, respectively. Scrambled siRNA and doxorubicin $(5 \mu \mathrm{g} / \mathrm{ml})$ were used as negative and positive controls for inhibition of cell growth as well as migration, respectively.

\subsection{Statistical analysis}

All results were presented as mean \pm standard deviation. Results were analyzed by one-way ANOVA with tukey's multiple comparison post-hoc test, where an asterisk (*) indicated significantly different groups in figures. The significance $(p<0.05)$ was typically determined by comparing specific siRNA-treated groups to that of scrambled siRNA-treated group. 


\section{Results}

\subsection{Characterization of siRNA/polymer complexes with HA incorporation}

We have previously shown effective silencing of aberrant proteins by delivering specific siRNAs by using PEI-LA as a single carrier [17,33]. The PEI-LA used in this study was derived from 1.2 kDa PEI and substituted with linoleic acid to give 2.6 LA per PEI. Here, we additionally introduced HA into the siRNA/polymer complexes to better facilitate the delivery of siRNA. We made siRNA/polymer complexes in two ways (Fig 1) using HA as an additive and a coating. The complexes were characterized for hydrodynamic diameter (Z-average) and surface charge ( $\zeta$-potential). The size of siRNA/PEI-LA complexes without HA was $\sim 200 \mathrm{~nm}$, and it was reduced to $\sim 100 \mathrm{~nm}$ as soon as a small amount of HA (1:0.05 siRNA:HA) was added to the complexes (Fig 2A). The size of complexes increased gradually in HA additive from 1:0.05 to 1:4 siRNA:HA ratios, reaching $~ 180 \mathrm{~nm}$, but excess HA reduced the complex size to $\sim 130 \mathrm{~nm}$ at the 1:8 siRNA:HA ratio. In contrast to HA additive complexes, the sizes of HA-coated complexes remained at $\sim 125 \mathrm{~nm}$ for all HA ratios used in the complexation process.

The $\zeta$-potential of the complexes was $+28 \mathrm{mV}$ in the absence of HA, which decreased gradually as the amount of HA was increased in both approaches (Fig 2B). The $\zeta$-potential was still in the positive range up to siRNA:HA ratio of $1: 1(+15 \mathrm{mV})$ for $\mathrm{HA}$ additive complexes, and it turned negative at higher HA ratios. In HA coated complexes, $\zeta$-potential decreased from +28 to $+21 \mathrm{mV}$ when a small amount of HA was added (1:0.05 siRNA:HA ratio), after which it was reduced to $-25 \mathrm{mV}$ for all other HA coatings.

To determine the stability of siRNA in complexes, the complexes were incubated in culture medium for 0,4 and $24 \mathrm{hrs}$ at $37^{\circ} \mathrm{C}$, and uptake of siRNA was determined by flow cytometry. As expected, the mean siRNA uptake decreased dramatically after 4 and 24 hrs of incubation in culture 
medium compared to fresh complexes (Supplementary Fig 1), which was due to decreased fluorescence of the FAM-labeled siRNA while incubating at $37{ }^{\circ} \mathrm{C}$ (data not shown). However, the siRNA positive population clearly showed that the more cells were transfected with HA-modified complexes compared to without HA complexes at both 4 and 24 hrs of complexes incubation in culture medium.

\subsection{Uptake of siRNA/PEI-LA/HA complexes}

The uptake of siRNA was determined by flow cytometry for siRNA/polymer complexes with different amounts of HA. The siRNA:PEI-LA complexes without HA was able to deliver siRNA successfully. However, mean fluorescence was markedly less compared to complexes having HA, where $\sim 80 \%$ of the cell population was transfected by the complexes (Fig 3A). HA additive and coating protocols exhibited a similar pattern of uptake; when a small amount of HA was introduced to complexes (1:0.05 siRNA:HA), the uptake of siRNA was 5 and 2 fold higher for HA additive and coating, respectively, compared to complexes without HA. Uptake was increased with the addition of more HA to a maximum with the 1:1 siRNA:HA ratio. The uptake of siRNA gradually decreased with higher amounts of HA in the complexes. The cell population positive for siRNA was $\sim 95 \%$ for the optimal siRNA/PEI-LA/HA complexes, while a lower percentage was noted in the complexes without HA. No autofluorescence of the complexes was detected as the mean fluorescence of non-treated and non-labeled scrambled siRNA-treated cells was similar.

To further investigate the uptake of siRNA, confocal microscopy was performed for HA additive (Fig 3B) and HA coated complexes (Fig 3C). As expected, no autofluorescence was observed for non-treated cells and non-labeled scrambled siRNA-treated cells (Fig 3Bi and Fig 3Ci). For siRNA/polymer complexes without HA, uptake of FAM-labeled siRNA was quite low compared to complexes with HA (Fig 3Bii and Fig 3Cii). With a small amount of HA in complexes (1:0.05 ratio of siRNA:HA), the transfection of siRNA has increased dramatically (Fig 3Biii and Fig 3Ciii). 
Confirming the flow cytometry data, the highest uptake was detected with 1:1 ratio of siRNA:HA (Fig 3Biv and Fig 3Civ), with uptake decreasing significantly with 1:8 ratio of siRNA:HA (Fig 3Bv and Fig $3 \mathrm{Cv})$.

The transfection efficiency of siRNA/polymer complexes was also determined by confocal microscopy over $72 \mathrm{hrs}$ of post-transfection. The number of complexes inside cells without HA (Supplementary Fig 2A) and with HA additive (Supplementary Fig 2B) was quantitated (Supplementary Fig 2C). Some heterogeneity among the cell population was evident, but average number of particles/cell was higher when HA was added into complexes compared to without HA at all time-points. However, no statistical difference between HA additive and without HA complexes was observed due to heterogeneity of complexes among the cell population.

\subsection{Role of CD44 in uptake of HA-modified complexes}

To assess the role of CD44 in the uptake of HA-modified complexes, CD44 was silenced with the specific siRNA, followed by uptake of FAM-labeled siRNA. No effect of CD44 silencing on siRNA uptake was observed for complexes without HA (1:6:0 siRNA:PEI-LA:HA ratio). A significant difference in uptake was found between CD44 siRNA-treated and scrambled siRNA-treated/nontreated cells with both HA additive and coated complexes (Fig 4A). Approximately $15 \%$ and $30 \%$ of decrease in siRNA uptake was observed for HA additive and coated complexes, respectively.

To determine the efficiency of silencing by the CD44 siRNA, CD44 protein and mRNA levels were determined by CD44 antibody staining and RT-qPCR, respectively. The siRNA complexes were formulated with/without $\mathrm{HA}$ as well to investigate the influence of HA on silencing efficiency. A significant reduction in the surface CD44 protein was observed with HA additive and coated complexes compared to scrambled siRNA complexes (Fig 4B). No reduction in surface CD44 protein was found when complexes were delivered without HA (1:6:0 siRNA:PEI-LA:HA ratio). CD44 transcripts were 
significantly reduced when CD44 siRNA was delivered with/without HA modified complexes (Fig 4C).

To compare siRNA uptake between high CD44 expressing and low CD44 expressing cells, the siRNA uptake in MDA-MB-231, SUM149PT and MCF7 cells were determined using FAM-labeled siRNA. MDA-MB-231 is known to be high CD44 expressing cells, while MCF7 is low CD44 expressing cells [34]. The levels of CD44 surface proteins, as determined by immunostaining (Fig 5A), clearly suggested overexpression of CD44 in MDA-MB-231 cells, while low-expression of CD44 in SUM149PT and MCF7 cells. A similar result was obtained when CD44 mRNA levels were analyzed by RT-qPCR (Fig 5B). No significant siRNA uptake difference was observed among different cells when complexes were delivered without HA (Fig 5C). However, approximately 20-30\% siRNA uptake difference was evident between the CD44-overexpressing MDA-MB-231 cells and two other low CD44-expressing SUM149PT and MCF7 cells. Compared to complexes without HA, however, 3-4 fold increased siRNA uptake with the HA-modified complexes was observed with all cell-lines.

\subsection{Cell growth inhibition with CDC20 siRNA/PEI-LA/HA complexes}

Functional efficacy of siRNA/PEI-LA/HA complexes was determined by delivering siRNA against CDC20 in MDA-MB-231 cells. CDC20 siRNA was delivered at low concentration of siRNA $(20 \mathrm{nM})$ with various amounts of HA into complexes ranging from 1:0.1 to 1:12 siRNA:HA ratios. Approximately $20 \%$ cell growth inhibition was observed when HA was not added to the complexes (Fig 6A and B). However, the efficacy of siRNA was increased to $\sim 40 \%$ cell growth inhibition when a small amount of HA (1:0.1 siRNA:HA ratio) was introduced into the HA additive (Fig 6A) and HA coated (Fig 6B) complexes, which remained constant until 1:1 siRNA:HA ratio. The effect of siRNA gradually diminished with increasing amounts of HA. Very little cell growth inhibition (5-10\%) was observed at the highest siRNA:HA ratio of 1:12. 


\subsection{Screening of phosphatases to identify targets for cell migration inhibition}

A total 267 phosphatase-specific siRNAs were employed to transfect MDA-MB-231 cells using PEI-LA as a delivery carrier, and the efficacy of siRNAs was determined by inhibition of cell growth (Fig 7A) and migration (Fig 7B). CDC20 siRNA was used as a positive control with the library screen, and $\sim 40 \%$ cell growth inhibition was observed with this siRNA during the screen. For the inhibition of migration assay, doxorubicin was additionally used as a positive control in the library screen, which inhibited $\sim 60 \%$ cell migration. Overall, more than $20 \%$ cell growth inhibition was obtained with $73 \%$ of phosphatase siRNAs, with CDC20 providing the most effective inhibition (Fig 7A). Similarly, numerous phosphatase-specific siRNAs inhibited the cellular migration of MDA-MB-231 (Fig 7B), again with CDC20 siRNA and doxorubicin acting as the most effective inhibitors. The effectiveness of the latter treatments was presumed to be due to indirect effects of cell proliferation inhibition. The extent of growth inhibition (POC from Fig 7A) and inhibition of migration (POC from Fig 7B) for each phosphatase siRNA was correlated in Fig 7C to identify specific targets that can inhibit migration of MDA-MB-231 cells specifically. Two groups of phosphatase siRNAs were identified accordingly: first group of phosphatases PPP1R7, PTPN22 and PPP1R12A siRNA inhibited cells migration drastically, but failed to inhibit cell growth. A second group of phosphatases PTPN1, LHPP and DUPD1 inhibited both cell migration and growth.

\subsection{Validation of identified phosphatase targets}

The efficacy of identified phosphatase siRNAs was validated with inhibition of MDA-MB-231 cell growth and migration by delivering individual siRNAs against each phosphatase using PEI-LA as a delivery agent. At $20 \mathrm{nM}$ siRNA, only PTPN1, LHPP and DUPD1 siRNAs inhibited cell migration significantly compared to scrambled siRNA-treated cells (Fig 8A). However, no growth inhibition was observed at $20 \mathrm{nM}$ siRNA (Fig 8D). MDA-MB-231 cells seemed responsive to all phosphatase siRNAs at $40 \mathrm{nM}$ even though a significant difference in inhibition of cell migration was observed with LHPP 
and PPP1R12A siRNAs only (Fig 8B). Similarly, only CDC20, PPP1R7, LHPP and DUPD1 siRNAs showed significant cell growth inhibition at $40 \mathrm{nM}$ siRNA (Fig 8E). The siRNA/PEI-LA complexes were toxic at $60 \mathrm{nM}$ siRNA as $\sim 50 \%$ inhibition of cell growth and $\sim 40 \%$ inhibition of cell migration was observed with the scrambled siRNA itself. However, the cells showed strong response at higher siRNA concentration as the migration of cells was inhibited completely with CDC20, PTPN1 and PTPN22 siRNAs at 1:3 siRNA:PEI-LA ratios (Fig 8C). Cell growth was also decreased significantly with CDC20, PPP1R7, PTPN1, PTPN22, PPP1R12A and DUPD1 siRNAs at higher concentration of siRNA (Fig 8F).

To further validate the inhibition of cell migration, Transwell migration assays were performed using phosphatase siRNAs with PEI-LA (Fig 9). No inhibition of MDA-MB-231 cell migration was observed with the scrambled siRNA-treated cells. Doxorubicin $(5 \mu \mathrm{g} / \mathrm{mL})$ that was used as a positive control, inhibited $\sim 80 \%$ cell migration, while CDC20 siRNA decreased the migration of cells by $\sim 20 \%$. Among all phosphatase siRNAs, PPP1R7, PTPN22 and PPP1R12A siRNAs inhibited the cell migration significantly compared to scrambled siRNA-treated cells, and PTPN22 inhibited the highest percentage of cell migration $(\sim 50 \%)$.

\subsection{Combinational siRNA therapy}

Once the identified phosphatase targets were validated, the combinational siRNA delivery of CDC20 and phosphatase siRNAs was performed with HA-formulated complexes. To assess silencing at the mRNA level, the changes in each phosphatase transcript levels was determined when delivered individually or in combination with CDC20 (Fig 10). All phosphatase siRNAs decreased the levels of transcripts significantly compared to scrambled siRNA-treated cells when those were delivered individually or in combination except DUPD1 siRNA. Interestingly, no decrease in the levels of DUPD1 transcripts was observed after siRNA delivery (consistent with a lack of reduction of migration in Fig 9), and slight increase in the transcripts levels was found compared to scrambled siRNA-treated 
transcripts. In contrast, CDC20 siRNA showed the highest amount of inhibition ( 80\%) of its mRNA among all siRNAs. No change in the efficiency of silencing CDC20 or phosphatase proteins was observed with the combinational siRNA delivery compared to individual siRNA delivery (Fig 10).

Finally, the functional evaluation of combinational siRNA delivery was performed for inhibition of cell growth and migration (Fig 11). Doxorubicin was used as a positive control and it inhibited the migration as well as growth of MDA-MB-231 cells significantly compared to non-treated cells. The CDC20 siRNA inhibited cell migration and growth (40-60\% inhibition) when delivered at 20 or $40 \mathrm{nM}$ concentrations. Individual PPP1R7, PTPN1, LHPP and PPP1R12A siRNAs decreased the migration of cells significantly compared to scrambled siRNA and failed to decrease the cell growth in HA additive complexes (Fig 11A). However, all phosphatase siRNAs inhibited cell migration and growth when delivered in combination with CDC20 except DUPD1 that failed to decrease the cell migration (Fig 11A). For HA-coated complexes, only PTPN1 siRNA decreased cell migration significantly, while no growth inhibition was found with all phosphatase siRNAs when those were delivered individually (Fig 11B). In contrast, cell migration and growth were inhibited significantly in the combinational siRNA delivery of phosphatase and CDC20 except DUPD1 again (Fig 11B). Overall, MDA-MB-231 cells treated with HA additive complexes showed more response compared to HA coated complexes, and both 1:3:1 and 1:6:1 siRNA:PEI-LA:HA ratios have shown similar results.

\section{Discussion}

RNAi-mediated knockdown of specific proteins using siRNA is a promising approach to target deregulated or over-expressed protein that could not be selectively targeted by chemotherapy $[6,7]$. However, siRNA-mediated silencing of specific targets has its own limitations; one of them is the need for non-toxic carriers that could easily transport siRNA without extracellular degradation, and release siRNA into cytoplasm, so that siRNA could incorporate into the RISC assembly [8]. To this end, we 
have developed a library of carriers based on lipid-substituted low molecular weight PEIs and have found linoleic acid-substituted 1.2 $\mathrm{kDa} \mathrm{PEI}$ to be most effective at delivering siRNA to breast cancer cells $[17,33]$. This report shows that introduction of HA into the complexation process further increases the delivery efficiency to breast cancer cells with higher cellular uptake of FAM-labeled siRNA when the complexes were formulated with HA additive and coating compared with complexes made without HA. Furthermore, confocal microscopy showed that the HA-mediated delivery of siRNA led to more sustained presence of siRNA intracellularly. One of the reasons for increased efficiency of complexes to deliver siRNA could be overexpression of surface receptor CD44 in triple-negative MDA-MB-231 cells [15,34]. Shen et al. have successfully shown an enhanced antitumor activity with HA coated lipid nanoparticles loaded with paclitaxel in CD44 over-expressing melanoma cells, and Yang et al. reported a targeted paclitaxel delivery by self-assembled HA coated lipid-based nanoparticles in CD44 overexpressing breast cancer cells [35,36], suggesting a high specificity of HA to bind CD44 for increased interactions with cell membrane, leading to increased uptake of siRNA. With the three cell-lines used in this study, we noted 3-4 fold increased siRNA uptake after HA incorporation into complexes, clearly indicating the beneficial effect of HA addition. A critical issue was whether this increase was solely attributed to CD44 receptors on the cells. Two lines of evidence argued against this; first, the CD44 levels were different between the MDA-MB-231 cells and SUM149PT/MCF7 cells, yet the increased uptake was relatively similar (only 20-30\% difference with HA-modified complexes), and second, silencing CD44 in MDA-MB-231 reduced the uptake of siRNA to some extent (15-30\%), but did not abolish the uptake to baseline levels (i.e., equivalent to complexes without HA). These observations, while confirming a role of CD44 surface receptor with HA-modified complexes, suggested another mechanism(s) of uptake to be responsible for the improved effect of complexes with HA modification. It is likely that improved physicochemical characteristics of complexes with HA addition might have played a role in the uptake of siRNA. Even though others showed CD44 expression to be significant for the efficacy of HA-modified nanoparticles [35,36], our results with PEI-LA/HA polymeric carrier 
suggests a minor role of CD44 for the uptake of siRNA, and the uptake seems to be mostly increasing by CD44 independent uptake pathway(s). Higher uptake of siRNA when complexed with HA clearly showed higher functional efficacy with CDC20 siRNA, which inhibited MDA-MB-231 cell growth more significantly compared to siRNA complexes without HA. In contrast, when excessive HA was incorporated into complexes, the uptake of siRNA decreased significantly and this correlated with a reduction in the efficiency of CDC20 siRNA delivered with these complexes to inhibit MDA-MB-231 cell growth. The poor efficacy of siRNA delivery at higher siRNA:HA ratios could be due to high negative $\zeta$-potential of complexes at excess HA incorporation.

The physicochemical characteristics of complexes impact greatly on the efficacy of siRNA treatment. The size of complexes became smaller with the addition of HA, which indicated a better compaction of siRNA into complexes, possibly due to better shielding of repulsive charges in the polyion complexes. The effect of HA on the $\zeta$-potential of complexes was more significant in decreasing the surface charge as high positive $\zeta$-potential could easily disrupt the cell membrane leading to cell death. Addition of HA into complexes decreased the surface charge of complexes, which may have played a major role during the interaction between complexes and the cell membrane including cell surface receptor CD44, resulting in a higher cellular uptake of siRNA. However, excessive HA into complexes leading to negative $\zeta$-potential might have impeded interactions of complexes with cell membrane, resulting in sub-optimal uptake of the complexes and silencing of the chosen targets. Moreover, addition of HA into complexes increased the stability of complexes in culture medium compared to without HA complexes (Supplementary Fig 1), given by 2-3 fold increased uptake for complexes incubated for 24 hours before addition to the cells.

Silencing the expression of cell cycle proteins is a promising approach to cancer therapy as the cell cycle is known to be deregulated in malignant cells and many cell cycle proteins are upregulated during malignancy [16]. One of the over-expressed proteins is CDC20, a critical protein for mitosis and cell division. We have previously validated siRNA therapy against CDC20 in breast cancer cells and 
shown a significant effect of silencing CDC20 in breast cancer cell survival in vitro and in an animal model [17]. Here, we observed a significant improvement in the inhibition of MDA-MB-231 cells by CDC20 siRNA delivery with the HA-incorporated complexes. In this study, CDC20 was mainly explored to develop a complementary siRNA therapy in conjunction with targeting phosphatase proteins that could be involved in metastasis. We relied on an unbiased approach using an siRNA library screen to identify potential phosphatase proteins as potential therapeutic targets for metastatic breast cancer. MDA-MB-231 cells were quite responsive to all phosphatases in terms of inhibition of cell growth and migration compared to non-invasive MDA-MB-435 and MCF7 cell-lines (data not shown), which was a clear indication that MDA-MB-231 cells are relying more on phosphatases for its survival. In contrast, a poor response of MDA-MB-231 cells to a kinase library screen compared to MDA-MB-435 cells [37] clearly suggests independence of MDA-MB-231 cells from kinases for its survival. From the library screen, we identified PPP1R7, PTPN1, PTPN22, LHPP, PPP1R12A and DUPD1 as potential targets for siRNA-mediated inhibition of migration. After evaluating these phosphatases individually, the combinational siRNA therapy with CDC20 was performed to decrease cell growth and migration simultaneously. No interference in the functional effect of inhibiting cell growth by CDC20 siRNA was observed by phosphatase siRNAs when those were delivered in combination. Similarly, no suppression in the functional effect of migration inhibition by phosphatase siRNA was observed by the combination with CDC20 siRNA. The combinational siRNA delivery showed mostly additive effects of CDC20 and phosphatase siRNAs in terms of cell growth inhibition by CDC20 siRNA and migration inhibition by phosphatase siRNAs. However, a synergistic effect in inhibition of migration by PTPN22 and CDC20 siRNAs was observed when those were delivered as HA additive complexes (Fig 11A). In addition, PPP1R7, PTPN22 and PPP1R12A siRNAs when combined with CDC20 siRNA showed a synergistic effect in migration inhibition when those were delivered as HA coated complexes (Fig 11B). 
Among the phosphatases identified, the downregulation of PPP1R7, PTPN22 and PPP1R12A resulted in inhibition of migration only without affecting cell growth. PPP1R7 is a subunit that regulates the activity of protein phosphatase $1 . \mathrm{PPP} 1 \mathrm{R} 7$ is required for completion of the mitotic cycle and for targeting protein phosphatase 1 to the mitotic kinetochores. PPP1R7 is over-expressed in several cancers including cervical, lung, colorectal, gastric and ovarian, and has been implicated in carcinogenesis [38,39]. While the PPP1R7 siRNA was effective on its own, the combinational delivery with CDC20 siRNA inhibited cell growth and migration drastically (Fig 11), suggesting an important role of PPP1R7 in survival of MDA-MB-231 cells and inhibiting its expression by siRNA may lead to increased therapeutic effect in metastatic breast cancer.

The second identified phosphatase, PTPN22 is a lymphoid-specific intracellular phosphatase that was initially described in the T-cell receptor signaling pathway, and has been reported to promote the survival of antigen stimulated chronic lymphocytic leukemia (CLL) cells by blocking B-cell receptor (BCR) related antigen-induced apoptosis [40]. Mutated PTPN22 has been reported in breast cancer [41], and Fasching et al. have listed PTPN22 as one of the predictive genes, whose mutations could potentially play a role in the pathogenesis or prognosis of breast cancer [42]. Inhibition of PTPN22 expression led to a decrease in the migration of MDA-MB-231 cells in both scratch and transwell migration assays in this study. No inhibition of cell growth and migration was observed with PTPN22 siRNA at low $20 \mathrm{nM}$ siRNA concentration when it was delivered individually (Fig 11), however, both were inhibited significantly when PTPN22 siRNA was combined with CDC20 siRNA. This is consistent with the ability of combinational siRNA therapy to lower the required dose of siRNA while obtaining significant inhibition of cell growth and migration simultaneously.

The third phosphatase that inhibited cell migration only was PPP1R12A, also called myosin phosphatase target subunit 1 (MYPT1) as it is one of the subunits of myosin phosphatase. Myosin II plays important roles in many contractile-like cell functions, such as cell migration, adhesion, and retraction $[43,44]$. Phosphorylation by regulatory light chain (RLC) activates myosin II, while its 
dephosphorylation by myosin phosphatase containing MYPT1 or PPP1R12A leads to myosin inactivation $[43,44]$. Phosphorylation of RLC is also involved in regulating aspects of cell migration and spreading $[44,45]$. Inhibiting the activities of myosin phosphatase by downregulating its subunit PPP1R12A increases the phosphorylation of RLC, which ultimately reduces the turnover of phosphorylation followed by the blocking of peripheral membrane ruffling as well as the assembly of stable focal adhesions, leading to decreased cell migration [46,47]. While targeting PPP1R12A might not be particularly specific for malignant cells (given its normal role in cell migration), PPP1R12A has been found upregulated in various cancer such as breast [48], pancreatic [49] and colorectal [50] cancers. We observed excellent reduction of PPP1R12A transcripts with siRNA and successful migration inhibition of MDA-MB-231 cells during validation studies, supporting its involvement in cell migration and adhesion. There was also improved efficiency of PPP1R12A siRNA in the combinational siRNA therapy with CDC20 siRNA, suggesting a potential candidate for siRNA therapy to inhibit the metastasis of other types of cancers in addition to breast cancer.

A second group of phosphatases, PTPN1, LHPP and DUPD1, inhibited cell migration as well as growth drastically in the library screen. PTPN1, also known as protein-tyrosine phosphatase 1B (PTP1B) is the founding member of the protein tyrosine phosphatase (PTP) family. PTPN1 is important in mammalian metabolism, where it negatively regulates the insulin signaling pathway. It has been considered as a promising therapeutic target for type 2 diabetes, in addition to several cancers [51]. PTPN1 has been shown to induce the growth of breast cancer tumors in mice [52], while breast cancer cell invasion and metastasis can be inhibited using small molecule inhibitors by downregulating PTPN1 [53,54]. We have shown here that siRNA against PTPN1 can inhibit breast cancer cell migration, while combinational siRNA therapy with CDC20 siRNA inhibited cell growth as well as migration.

LHPP (phospholysine phosphohistidine inorganic pyrophosphate phosphatase) is an inorganic pyrophosphatase that hydrolyzes phospholysine and phosphohistidine, and has a broad substrate 
specificity. Inorganic pyrophosphatase controls the level of inorganic pyrophosphate produced by biosynthesis of protein, RNA, and DNA. Over-expression of LHPP is known to be associated with hyperthyroidism [55]. No studies have been reported so far about the involvement of LHPP in cancer, however, it has been suggested that over-expression of the protein in hyperthyroidism may contribute to carcinogenesis in the thyroid [55]. We observed relatively poor efficacy of LHPP siRNA to decrease the migration of MDA-MB-231 cells, but the combinational siRNA therapy of LHPP and CDC20 decreased cell migration and growth significantly.

DUPD1, also known as dual specificity phosphatase 27 (DUSP27), is a recently identified dualspecificity phosphatase that can dephosphorylate both phosphotyrosine and phosphoserine/threonine residues. It is a member of the protein-tyrosine phosphatase superfamily that cooperates with protein kinases to regulate cell proliferation and differentiation. Although there is no clear involvement with cancer, DUPD1 is over-expressed in pancreatic cancer [56] and liver metastasis of colorectal cancer [57]. In the present study, DUPD1 siRNA showed the highest efficacy in terms of cell growth and migration inhibitions in the library screen. However, no cell migration inhibition was observed with DUPD1 siRNA in the validation studies nor the combinational siRNA therapy. This discrepancy is likely due to the lack of effective downregulation of the DUPD1 transcript by DUPD1 siRNA delivery (Fig 10). The siRNA that was used in the validation study was dicer-substrate siRNA, which is 27-mer and expected to provide higher efficacy [58]. However, no downregulation of DUPD1 transcripts by siRNA indicates poor functional outcome of siRNA by failing the translational inhibition of DUPD1 mRNA when it was delivered to cytoplasm of MDA-MB-231 cells. Perhaps, a better siRNA design that has high functionality and specificity may resolve this paradox.

\section{Conclusions}


We have established a novel polymeric siRNA delivery carrier based on PEI-LA/HA that could serve as a viable platform to target breast cancer cells. As cellular uptake of siRNA greatly increased with the addition of HA into the delivery system, a more favorable interaction of siRNA/polymer complexes with the triple-negative breast cancer cells was evident compared to complexes without HA. The cell-surface receptor CD44 played a role in increased uptake, but that did not appear to be the sole mechanism for siRNA delivery into the cells, and improved physicochemical characteristics might have played a significant role. While CDC20 siRNA showed an excellent and consistent ability to inhibit triple-negative breast cancer cells, more validation of siRNAs against phosphatases is needed. This may include in vivo studies confirming the functional validity of phosphatase siRNAs to inhibit cell migration and metastasis. The identified phosphatases could serve as potential targets to inhibit migration of highly aggressive breast cancer cells. Moreover, combinational siRNA delivery against cell cycle and phosphatases could be a promising strategy to inhibit both growth and migration of metastatic breast cancer cells. These could be further developed to treat other types of metastatic cancer.

\section{Acknowledgements}

Manoj Parmar is a recipient of Women and Children's Health Research Institute (WCHRI) and Alberta Innovates-Health Solutions (AIHS) Graduate Studentships. This study was supported by operating grants from Canadian Breast Cancer Foundation (CBCF) and Natural Sciences and Engineering Council of Canada (NSERC). 


\section{References}

1. B. Weigelt, J.L. Peterse, L.J. van't Veer, Breast cancer metastasis: markers and models, Nat. Rev. Cancer. 5 (2005) 591-602.

2. M. Rahman, S. Mohammed, Breast cancer metastasis and the lymphatic system, Oncol. Lett. 10 (2015) 1233-1239.

3. G. Ligresti, M. Libra, L. Militello, S. Clementi, M. Donia, R. Imbesi, G. Malaponte, A. Cappellani, J.A. McCubrey, F. Stivala, Breast cancer: Molecular basis and therapeutic strategies, Mol. Med. Rep. 1 (2008) 451-458.

4. P. Vici, L. Pizzuti, C. Natoli, T. Gamucci, L. Di Lauro, M. Barba, D. Sergi, C. Botti, A. Michelotti, L. Moscetti, L. Mariani, F. Izzo, L. D'Onofrio, I. Sperduti, F. Conti, V. Rossi, A. Cassano, M. Maugeri-Saccà, M. Mottolese, P. Marchetti, Triple positive breast cancer: a distinct subtype? Cancer Treat. Rev. 41 (2015) 69-76.

5. R. Dent, M. Trudeau, K. Pritchard, W.M. Hanna, H.K. Kahn, C.A. Sawka, L.A. Lickley, E. Rawlinson, P. Sun, S.A. Narod, Triple-negative breast cancer: clinical features and patterns of recurrence, Clin. Cancer Res. 13 (2007) 4429-4434.

6. M.T. McManus, P.A. Sharp, Gene silencing in mammals by small interfering RNAs, Nat. Rev. Genet. 3 (2002) 737-747.

7. R.C. Wilson, J.A. Doudna, Molecular mechanisms of RNA interference, Annu. Rev. Biophys. 42 (2013) 217-239.

8. C.V. Pecot, G.A. Calin, R.L. Coleman, G. Lopez-Berestein, A.K. Sood, RNA interference in the clinic: Challenges and future directions, Nat. Rev. Cancer. 11 (2011) 59-67.

9. H.M. Aliabadi, B. Landry, C. Sun, T. Tang, H. Uludag, Supramolecular assemblies in functional siRNA delivery: where do we stand? Biomaterials. 33 (2012) 2546-2569. 
10. H.M. Aliabadi, B. Landry, R.K. Bahadur, A. Neamnark, O. Suwantong, H. Uludag, Impact of lipid substitution on assembly and delivery of siRNA by cationic polymers, Macromol. Biosci. 11 (2011) $662-672$.

11. R.B. KC, C. Kucharski, H. Uludag, Additive nanocomplexes of cationic lipopolymers for improved non-viral gene delivery to mesenchymal stem cells, J. Mater. Chem. B. 3 (2015) 3972-3982.

12. J.R. Fraser, T.C. Laurent, U.B. Laurent, Hyaluronan: its nature, distribution, functions and turnover, J. Intern. Med. 242 (1997) 27-33.

13. A. Aruffo, I. Stamenkovic, M. Melnick, C.B. Underhill, B. Seed, CD44 is the principal cell surface receptor for hyaluronate, Cell. 61 (1990) 1303-1313.

14. G. Mattheolabakis, L. Milane, A. Singh, M.M. Amiji, Hyaluronic acid targeting of CD44 for cancer therapy: from receptor biology to nanomedicine, J. Drug. Target. 23 (2015) 605-618.

15. M.O. Idowu, M. Kmieciak, C. Dumur, R.S. Burton, M.M. Grimes, C.N. Powers, M.H. Manjili, $\mathrm{CD} 44^{+} / \mathrm{CD} 24^{-/ \text {low }}$ cancer stem/progenitor cells are more abundant in triple-negative invasive breast carcinoma phenotype and are associated with poor outcome, Hum. Pathol. 43 (2012) 364-373.

16. C. Sandhu, J. Slingerland, Deregulation of the cell cycle in cancer, Cancer Detect. Prev. 24 (2000) $107-118$.

17. M.B. Parmar, H.M. Aliabadi, P. Mahdipoor, C. Kucharski, R. Maranchuk, J.C. Hugh, H. Uludag, Targeting cell cycle proteins in breast cancer cells with siRNA by using lipid-substituted polyethylenimines, Front. Bioeng. Biotechnol. 3 (2015) 14.

18. Y. Kimata, J.E. Baxter, A.M. Fry, H. Yamano, A role for the Fizzy/ Cdc20 family of proteins in activation of the APC/C distinct from substrate recruitment, Mol. Cell. 32 (2008) 576-583.

19. T. Motiwala, S.T. Jacob, Role of protein tyrosine phosphatases in cancer, Prog. Nucleic Acid Res. Mol. Biol. 81 (2006) 297-329.

20. A.Q. Al-Aidaroos, Q. Zeng, PRL-3 phosphatase and cancer metastasis, J. Cell. Biochem. 111 (2010) 1087-1098. 
21. D.C. Bessette, D. Qiu, C.J. Pallen, PRL PTPs: mediators and markers of cancer progression, Cancer Metastasis Rev. 27 (2008) 231-252.

22. S. Saha, A. Bardelli, P. Buckhaults, V.E. Velculescu, C. Rago, B. St Croix, K.E. Romans, M.A. Choti, C. Lengauer, K.W. Kinzler, B. Vogelstein, A phosphatase associated with metastasis of colorectal cancer, Science. 294 (2001) 1343-1346.

23. S.T. Lee, M. Feng, Y. Wei, Z. Li, Y. Qiao, P. Guan, X. Jiang, C.H. Wong, K. Huynh, J. Wang, J. Li, K.M. Karuturi, E.Y. Tan, D.S. Hoon, Y. Kang, Q. Yu, Protein tyrosine phosphatase UBASH3B is overexpressed in triple-negative breast cancer and promotes invasion and metastasis, Proc. Natl. Acad. Sci. U.S.A. 110 (2013) 11121-11126.

24. K. Spring, P. Fournier, L. Lapointe, C. Chabot, J. Roussy, S. Pommey, J. Stagg, I. Royal, The protein tyrosine phosphatase DEP-1/PTPRJ promotes breast cancer cell invasion and metastasis, Oncogene. 34 (2015) 5536-5547.

25. X. Feng, Z. Wu, Y. Wu, W. Hankey, T.W. Prior, L. Li, R.K. Ganju, R. Shen, X. Zou, CDC25A regulates matrix metalloprotease 1 through Foxo1 and mediates metastasis of breast cancer cells, Mol. Cell. Biol. 31 (2011) 3457-3471.

26. K.C. Bahadur, B. Landry, H.M. Aliabadi, A. Lavasanifar, H. Uludag, Lipid substitution on low molecular weight $(0.6-2.0 \mathrm{kDa})$ polyethylenimine leads to a higher zeta potential of plasmid DNA and enhances transgene expression, Acta. Biomater. 7 (2011) 2209-2217.

27. Remant Bahadur KC, H. Uludag, A comparative evaluation of disulfide-linked and hydrophobically-modified PEI for plasmid delivery, J. Biomater. Sci. Polym. Ed. 22 (2011) 873892.

28. V.N. Sumantran, Cellular chemosensitivity assays: An overview, Methods Mol. Biol. 731 (2011) 219-236.

29. C.C. Liang, A.Y. Park, J.L. Guan, In vitro scratch assay: a convenient and inexpensive method for analysis of cell migration in vitro, Nat. Protoc. 2 (2007) 329-333. 
30. C.A. Schneider, W.S. Rasband, K.W. Eliceiri, NIH Image to ImageJ: 25 years of image analysis, Nat. Methods. 9 (2012) 671-675.

31. T. Gebäck, M.M. Schulz, P. Koumoutsakos, M. Detmar, TScratch: a novel and simple software tool for automated analysis of monolayer wound healing assays, Biotechniques. 46 (2009) 265-274.

32. K.J. Livak, T.D. Schmittgen, Analysis of relative gene expression data using real-time quantitative PCR and the $2^{-\Delta \Delta C}$ method, Methods. 25 (2001) 402-408.

33. M.B. Parmar, B.E. Arteaga Ballesteros, T. Fu, R.B. KC, H. Montazeri Aliabadi, J.C. Hugh, R. Löbenberg, H. Uludağ, Multiple siRNA delivery against cell cycle and anti-apoptosis proteins using lipid-substituted polyethylenimine in triple-negative breast cancer and nonmalignant cells, J. Biomed. Mater. Res. A. 104 (2016) 3031-3044.

34. C. Sheridan, H. Kishimoto, R.K. Fuchs, S. Mehrotra, P. Bhat-Nakshatri, C.H. Turner, R. Jr Goulet, S. Badve, H. Nakshatri, CD44+/CD24- breast cancer cells exhibit enhanced invasive properties: an early step necessary for metastasis, Breast Cancer Res. 8 (2006) R59.

35. H. Shen, S. Shi, Z. Zhang, T. Gong, X. Sun, Coating solid lipid nanoparticles with hyaluronic acid enhances antitumor activity against melanoma stem-like cells, Theranostics. 5 (2015) 755-771.

36. C. Yang, Y. He, H. Zhang, Y. Liu, W. Wang, Y. Du, F. Gao, Selective killing of breast cancer cells expressing activated CD44 using CD44 ligand-coated nanoparticles in vitro and in vivo, Oncotarget. $6(2015)$ 15283-15296.

37. H.M. Aliabadi, R. Maranchuk, C. Kucharski, P. Mahdipoor, J. Hugh, H. Uludağ, Effective response of doxorubicin-sensitive and -resistant breast cancer cells to combinational siRNA therapy, J. Control. Release. 172 (2013) 219-228.

38. S. Takakura, T. Kohno, R. Manda, A. Okamoto, T. Tanaka, J. Yokota, Genetic alterations and expression of the protein phosphatase 1 genes in human cancers, Int. J. Oncol. 18 (2001) 817-824.

39. Y. Harima, K. Ikeda, K. Utsunomiya, T. Shiga, A. Komemushi, H. Kojima, M. Nomura, M. Kamata, S. Sawada, Identification of genes associated with progression and metastasis of advanced 
cervical cancers after radiotherapy by cDNA microarray analysis, Int. J. Radiat. Oncol. Biol. Phys. 75 (2009) 1232-1239.

40. R. Negro, S. Gobessi, P.G. Longo, Y. He, Z.Y. Zhang, L. Laurenti, D.G. Efremov, Overexpression of the autoimmunity-associated phosphatase PTPN22 promotes survival of antigen-stimulated CLL cells by selectively activating AKT, Blood. 119 (2012) 6278-6287.

41. Cancer Genome Atlas Network, Comprehensive molecular portraits of human breast tumors, Nature. 490 (2012) 61-70.

42. P.A. Fasching, S.Y. Brucker, T.N. Fehm, F. Overkamp, W. Janni, M. Wallwiener, P. Hadji, E. Belleville, L. Häberle, F.A. Taran, D. Lüftner, M.P. Lux, J. Ett1, V. Müller, H. Tesch, D. Wallwiener, A. Schneeweiss, Biomarkers in patients with metastatic breast cancer and the PRAEGNANT study network, Geburtshilfe Frauenheilkd. 75 (2015) 41-50.

43. Y.N. Qiao, W.Q. He, C.P. Chen, C.H. Zhang, W. Zhao, P. Wang, L. Zhang, Y.Z. Wu, X. Yang, Y.J. Peng, J.M. Gao, K.E. Kamm, J.T. Stull, M.S. Zhu, Myosin phosphatase target subunit 1 (MYPT1) regulates the contraction and relaxation of vascular smooth muscle and maintains blood pressure, J. Biol. Chem. 289 (2014) 22512-22523.

44. T. Wakatsuki, R.B. Wysolmerski, E.L. Elson, Mechanics of cell spreading: role of myosin II, J. Cell. Sci. 116 (2003) 1617-1625.

45. K. Kaneko, K. Satoh, A. Masamune, A. Satoh, T. Shimosegawa, Myosin light chain kinase inhibitors can block invasion and adhesion of human pancreatic cancer cell lines, Pancreas. 24 (2002) 34-41.

46. D. Xia, J.T. Stull, K.E. Kamm, Myosin phosphatase targeting subunit 1 affects cell migration by regulating myosin phosphorylation and actin assembly, Exp. Cell. Res. 304 (2005) 506-517.

47. G. Totsukawa, Y. Wu, Y. Sasaki, D.J. Hartshorne, Y. Yamakita, S. Yamashiro, F. Matsumura, Distinct roles of MLCK and ROCK in the regulation of membrane protrusions and focal adhesion dynamics during cell migration of fibroblasts, J. Cell. Biol. 164 (2004) 427-439. 
48. M. Cuadros, C. Cano, F.J. López, R. López-Castro, A. Concha, Expression profiling of breast tumors based on human epidermal growth factor receptor 2 status defines migration-related genes, Pathobiology. 80 (2013) 32-40.

49. A. Van den Broeck, H. Vankelecom, R. Van Eijsden, O. Govaere, B. Topal, Molecular markers associated with outcome and metastasis in human pancreatic cancer, J. Exp. Clin. Cancer. Res. 31 (2012) 68.

50. C. Zhang, A. Li, H. Li, K. Peng, Q. Wei, M. Lin, Z. Liu, L. Yin, J. Li, PPP1R12A copy number is associated with clinical outcomes of stage III CRC receiving oxaliplatin-based chemotherapy, Mediators. Inflamm. 2015 (2015) 417184.

51. L. Lessard, M. Stuible, M.L. Tremblay, The two faces of PTP1B in cancer, Biochim. Biophys. Acta. 1804 (2010) 613-619.

52. M. Bentires-Alj, B.G. Neel, Protein-tyrosine phosphatase 1B is required for HER2/Neu-induced breast cancer, Cancer Res. 67 (2007) 2420-2424.

53. S.G. Julien, N. Dubé, M. Read, J. Penney, M. Paquet, Y. Han, B.P. Kennedy, W.J. Muller, M.L. Tremblay, Protein tyrosine phosphatase 1B deficiency or inhibition delays ErbB2-induced mammary tumorigenesis and protects from lung metastasis, Nat. Genet. 39 (2007) 338-346.

54. C.L. Cortesio, K.T. Chan, B.J. Perrin, N.O. Burton, S. Zhang, Z.Y. Zhang, A. Huttenlocher, Calpain 2 and PTP1B function in a novel pathway with Src to regulate invadopodia dynamics and breast cancer cell invasion, J. Cell. Biol. 180 (2008) 957-971.

55. E. Koike, S. Toda, F. Yokoi, K. Izuhara, N. Koike, K. Itoh, K. Miyazaki, H. Sugihara, Expression of new human inorganic pyrophosphatase in thyroid diseases: its intimate association with hyperthyroidism, Biochem. Biophys. Res. Commun. 341 (2006) 691-696.

56. C. Pilarsky, O. Ammerpohl, B. Sipos, E. Dahl, A. Hartmann, A. Wellmann, T. Braunschweig, M. Löhr, R. Jesenofsky, H. Friess, M.N. Wente, G. Kristiansen, B. Jahnke, A. Denz, F. Rückert, H.K. Schackert, G. Klöppel, H. Kalthoff, H.D. Saeger, R. Grützmann, Activation of Wnt signaling in 
stroma from pancreatic cancer identified by gene expression profiling, J. Cell. Mol. Med. 12 (2008) 2823-2835.

57. J.M. Sayagués, L.A. Corchete, M.L. Gutiérrez, M.E. Sarasquete, M. Del Mar Abad, O. Bengoechea, E. Fermiñán, M.F. Anduaga, S. Del Carmen, M. Iglesias, C. Esteban, M. Angoso, J.A. Alcazar, J. García, A. Orfao, L. Muñoz-Bellvis, Genomic characterization of liver metastases from colorectal cancer patients, Oncotarget. 7 (2016) 72908-72922.

58. D.H. Kim, M.A. Behlke, S.D. Rose, M.S. Chang, S. Choi, J.J. Rossi, Synthetic dsRNA Dicer substrates enhance RNAi potency and efficacy, Nat. Biotechnol. 23 (2005) 222-226. 


\section{Figure Legends}

Figure 1: Schematic representation of the formulated siRNA/polymer complexes. The complexes were prepared by two methods. (A) HA Additive: siRNA was first mixed with HA followed by the addition of PEI-LA in the presence of $150 \mathrm{mM} \mathrm{NaCl}$ with 30 min of incubation to form complexes. (B) HA Coating: The complexes of siRNA/PEI-LA were first prepared in the presence of $150 \mathrm{mM} \mathrm{NaCl}$ with 30 min of incubation followed by the coating of HA for $30 \mathrm{~min}$ to siRNA/PEI-LA complexes.

Figure 2: Size and $\zeta$-potential of siRNA/polymer complexes. Size (A) and surface charge (B) of the complexes were determined for siRNA:PEI-LA (1:6 w/w ratio) complexes with various amounts of HA added to the complexes as additive and coating. The siRNA:HA ratios were 1:0, 1:0.05, 1:0.5, 1:1, 1:4 and 1:8 for the complexes.

Figure 3: Cellular uptake of siRNA/polymer complexes after $24 \mathrm{hr}$ of transfection. (A) Uptake of FAM-labeled siRNA by flow cytometry was determined using $40 \mathrm{nM}$ siRNA at 1:6 siRNA:PEI-LA w/w ratio with various amounts of HA. The mean fluorescence (i) and siRNA positive cell population (ii) were calculated for siRNA:HA w/w ratios 1:0, 1:0.05, 1:0.5, 1:1, 1:4 and 1:8. As a negative controls, non-labeled siRNA was delivered to MDA-MB-231 cells with 1:6:0 and 1:6:1 siRNA:PEILA:HA w/w/w ratios. (B) Uptake of FAM-labeled siRNA by confocal microscopy was determined for HA additive complexes. Non-labeled siRNA was transfected at 1:6:1 siRNA:PEI-LA:HA w/w/w ratio (i) as a negative control. Uptake of FAM-labeled siRNA was determined at 1:6:0 (ii), 1:6:0.05 (iii), 1:6:1 (iv) and 1:6:8 (v) siRNA:PEI-LA:HA w/w/w ratios. (C) Cellular uptake of siRNA by confocal microscopy for HA coating with similar groups as in HA additive. Purple, red and green colors represent nuclei, cytoplasm and FAM-labeled siRNA complexes, respectively. 
Figure 4: Cellular uptake of siRNA/polymer complexes after CD44 silencing. (A) MDA-MB-231 cells were transfected with $60 \mathrm{nM}$ of CD44 siRNA at 1:6:1 siRNA:PEI-LA:HA w/w/w ratio. After 72 hrs of CD44 siRNA treatment, FAM-labeled siRNA was added to the cells for 4 hrs at 1:6:0 and 1:6:1 siRNA:PEI-LA:HA w/w/w ratios with HA additive and coated complexes, followed by siRNA uptake analysis by flow cytometry. (B) CD44 silencing at surface protein levels determined by immunostaining. MDA-MB-231 cells were transfected with $60 \mathrm{nM}$ of CD44 siRNA at 1:6:0 and 1:6:1 siRNA:PEI-LA:HA w/w/w ratios. After 72 hrs of CD44 siRNA treatment, cells were stained with PElabeled anti-human CD44 antibody for $1 \mathrm{hr}$ followed by flow cytometry. PE-labeled anti-human IgG was used as a negative control antibody. (C) CD44 silencing was confirmed by RT-qPCR with $60 \mathrm{nM}$ siRNA at 1:6:0 and 1:6:1 siRNA:PEI-LA:HA w/w/w ratios. Scrambled siRNA (CsiRNA) was used as a negative control. The asterisks represent the significant reduction in cellular uptake of siRNA or CD44 surface protein or CD44 transcripts compared to CsiRNA $(p<0.05)$.

Figure 5: (A) The levels of CD44 surface protein in MDA-MB-231, SUM149PT and MCF7 cells determined by immunostaining. Cells were stained with PE-labeled anti-human CD44 antibody for $1 \mathrm{hr}$ followed by flow cytometry. PE-labeled anti-human IgG was used as a negative control antibody (not shown). (B) The levels of CD44 transcripts determined by RT-qPCR in MDA-MB-231, SUM149PT and MCF7 cells. (C) Cellular uptake of siRNA/polymer complexes in MDA-MB-231, SUM149PT and MCF7 cells. Cells were transfected with $40 \mathrm{nM}$ of FAM-labeled siRNA at 1:6:0 and 1:6:1 siRNA:PEILA:HA w/w/w ratio. After 24 hrs, siRNA uptake was analyzed by flow cytometry. The asterisks represent the significant decrease in CD44 surface protein or CD44 transcripts or cellular uptake of siRNA in SUM149PT/MCF7 compared to MDA-MB-231 cells $(p<0.05)$.

Figure 6: Functional evaluation of HA in siRNA/polymer complexes. The cell growth inhibition by CDC20 siRNA at $20 \mathrm{nM}$ was determined by siRNA/polymer complexes prepared with various amounts 
of HA, ranging from 1:0.1 to 1:12 siRNA:HA w/w ratios. Complexes were formulated with HA additive (A) and HA coating (B). Scrambled siRNA (CsiRNA) was used as a negative control. The asterisks represent the significant cell growth inhibition by CDC20 siRNA compared to CsiRNA $(p<$ $0.05)$.

Figure 7: Phosphatase siRNA library screening in MDA-MB-231 cells. (A) Inhibition of cell growth by phosphatase-specific siRNAs at $40 \mathrm{nM}$ with 1:6 siRNA:PEI-LA w/w ratio was determined as percentage of control siRNA-treated cell (POC). Black solid dot represents inhibition of cell growth by CDC20 siRNA delivery. (B) Inhibition of cell migration by phosphatase siRNA delivery was determined relative to control siRNA (POC). Green solid dot represents inhibition of cell growth by doxorubicin that was a positive control. (C) The correlation between inhibition of cell growth and migration by phosphatase siRNAs to reveal phosphatases that inhibited cell migration drastically (red solid dots).

Figure 8: Validation of identified phosphatase targets for cell migration $(\mathbf{A}, \mathbf{B}, \mathbf{C})$ and growth $(\mathbf{D}, \mathbf{E}$, F) inhibitions at 20,40 and $60 \mathrm{nM}$ siRNA with 1:3 and 1:6 siRNA:PEI-LA w/w ratios. Non-treated cells (NT) and scrambled siRNA-treated cells (CsiRNA) were presented as negative controls, while doxorubicin (DOX) was chosen as a positive control for the validation study. The asterisks represent significant inhibition of cell migration or growth by phosphatase siRNAs compared to CsiRNA $(p<$ $0.05)$.

Figure 9: Effects of phosphatase silencing on MDA-MB-231 migration by transwell migration assay at $40 \mathrm{nM}$ siRNA with 1:6 siRNA:PEI-LA w/w ratio. (A) Percentage of cell migration was determined based on non-treated cells. Scrambled siRNA-treated cells (CsiRNA) seeded in a well with fetal bovine serum (FBS) was used as a negative control, while incubation without FBS was considered as an 
additional control for inhibition. Doxorubicin with strong anti-growth activity was also used as a positive control. (B) Crystal violate stained migrated cells for scrambled siRNA-treated cells incubated with FBS (i), scrambled siRNA-treated cells without FBS (ii), and for cells treated with doxorubicin (iii), CDC20 (iv), PPP1R7 (v), PTPN1 (vi), PTPN22 (vii), LHPP (viii), PPP1R12A (ix) and DUPD1 (x) siRNAs. The asterisks represent the significant inhibition of cell migration by phosphatase siRNAs compared to CsiRNA $(p<0.05)$.

Figure 10: $R$ T-qPCR analysis to determine the silencing efficiency of individual and combinational siRNAs at total $40 \mathrm{nM}(20+20 \mathrm{nM})$ concentration with 1:3:1 and 1:6:1 siRNA:PEI-LA:HA w/w/w ratios against CDC20 and phosphatases for HA additive (A) and coated (B) complexes. Scrambled siRNA (CsiRNA) was used as a negative control. The asterisks represent the significant silencing of individual and combinational targets by specific siRNAs compared to CsiRNA $(p<0.05)$.

Figure 11: Inhibition of MDA-MB-231 growth and migration by individual siRNAs (20 nM phosphatase $+20 \mathrm{nM}$ scrambled siRNA) and combinational siRNAs $(20 \mathrm{nM}$ CDC20 + $20 \mathrm{nM}$ phosphatase) at 1:3:1 and 1:6:1 siRNA:PEI-LA:HA w/w/w ratios using HA additive (A) and coated (B) complexes. Percentage of cell migration and growth was determined based on non-treated cells. Scrambled siRNA (CsiRNA) was used as a negative control. The asterisks represent the significant cell growth or migration inhibition by individual and combinational siRNAs compared to CsiRNA $(p<$ $0.05)$. 
Figure 1

\section{A: HA Additive}

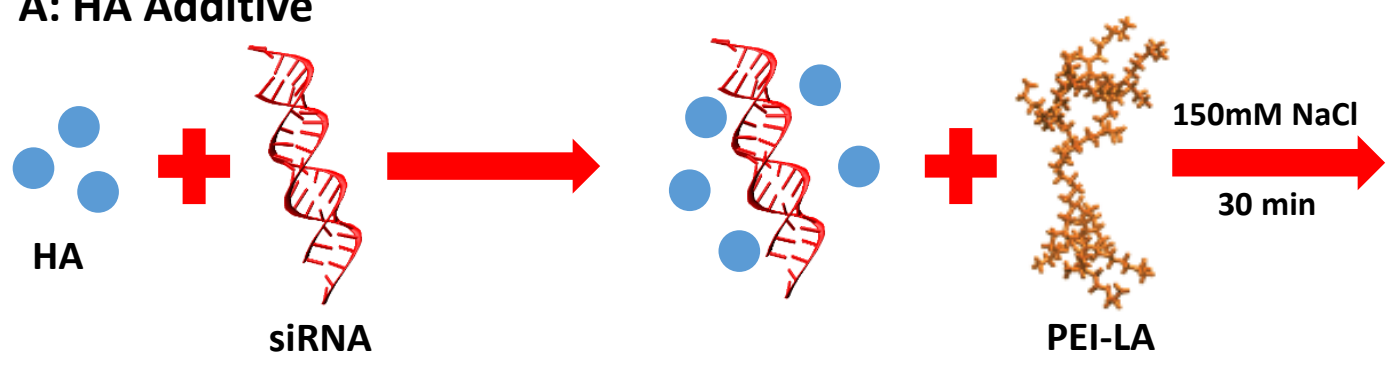

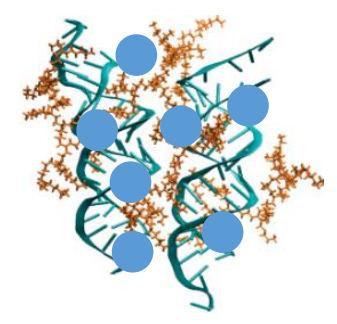

Complexes

\section{B: HA Coating}
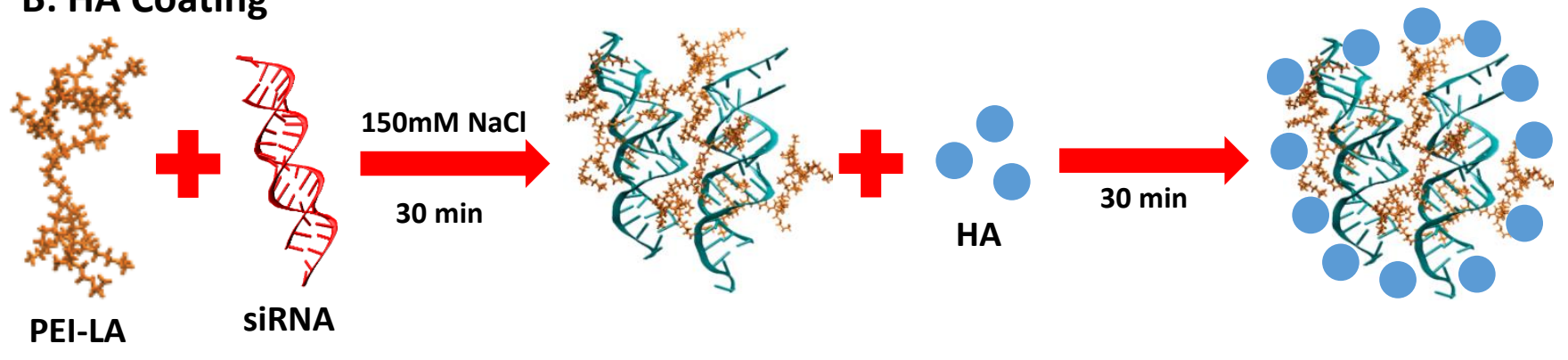
Figure 2

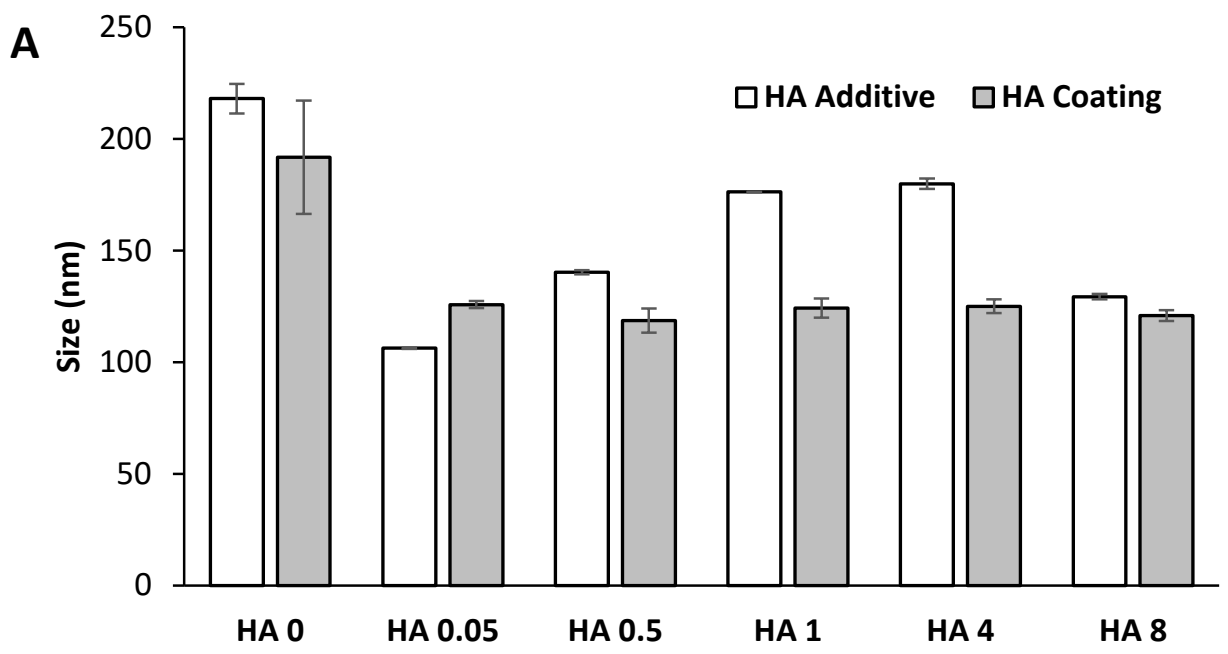

B

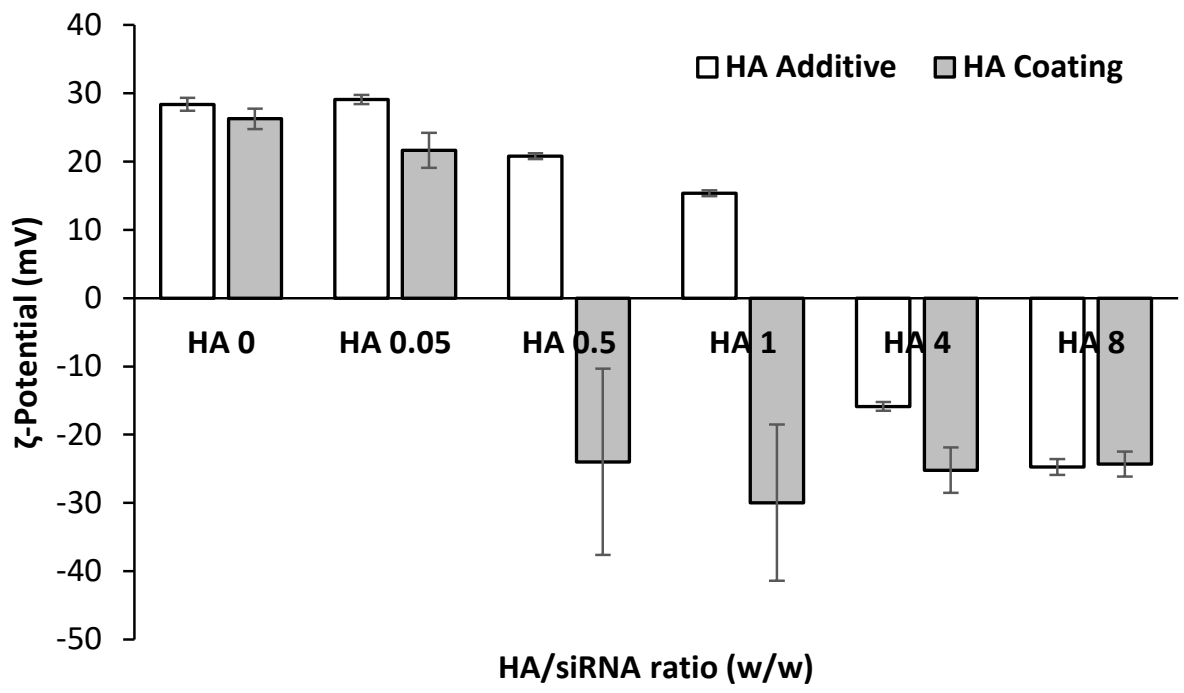


A
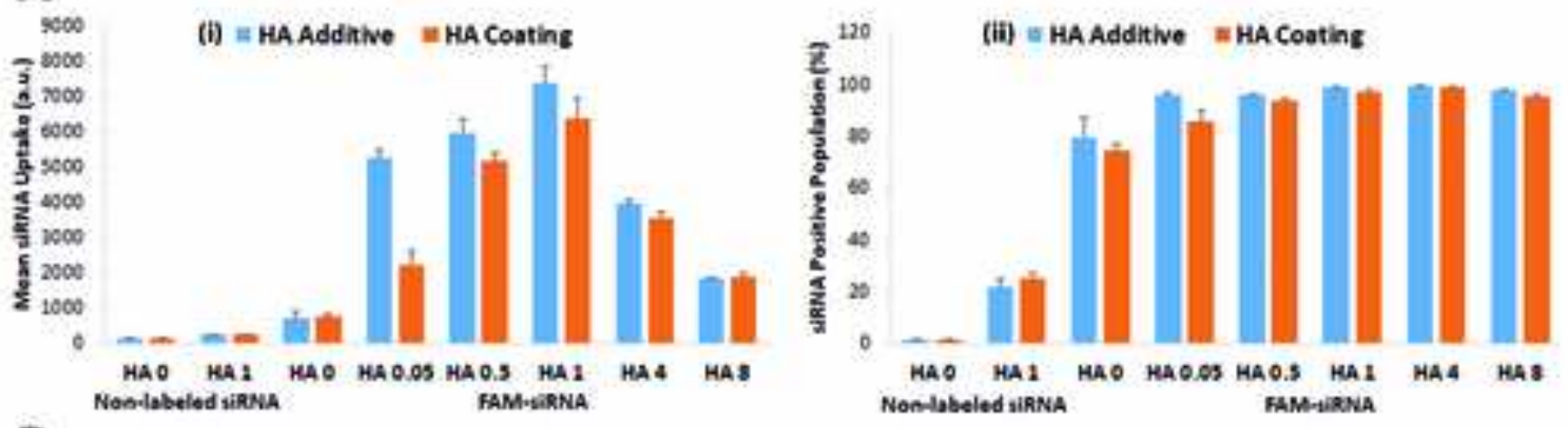

\section{B: HA Additive}
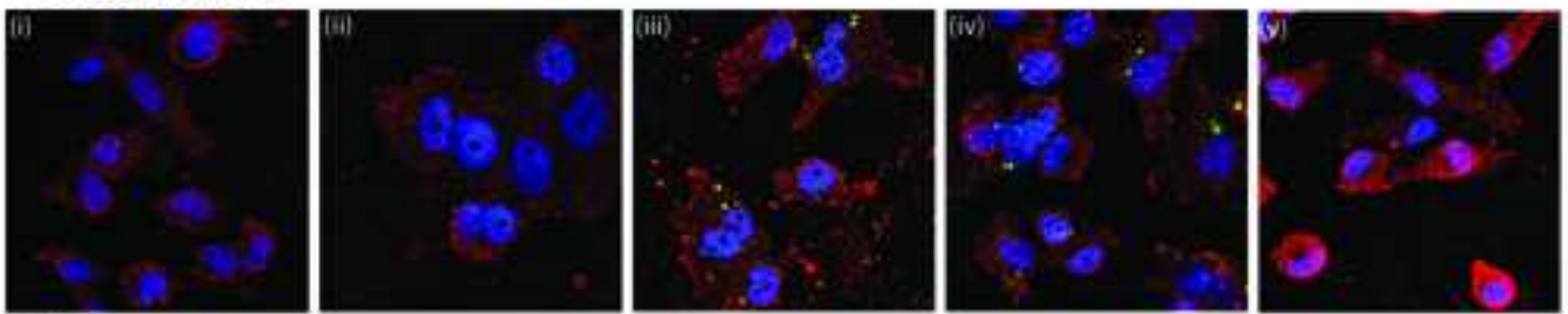

\section{C: HA Coating}
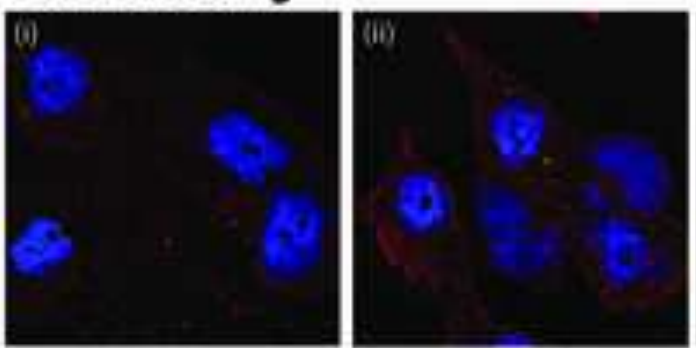

HA1

HAO

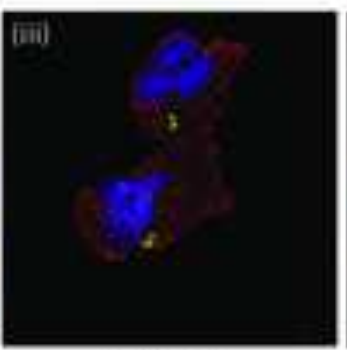

HA0.05

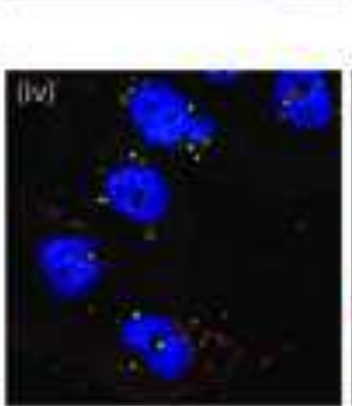

HA1

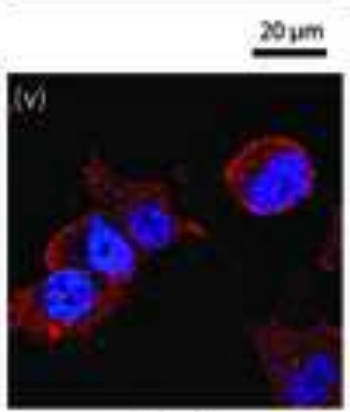

HA8 


\section{Figure 4}

\section{A}
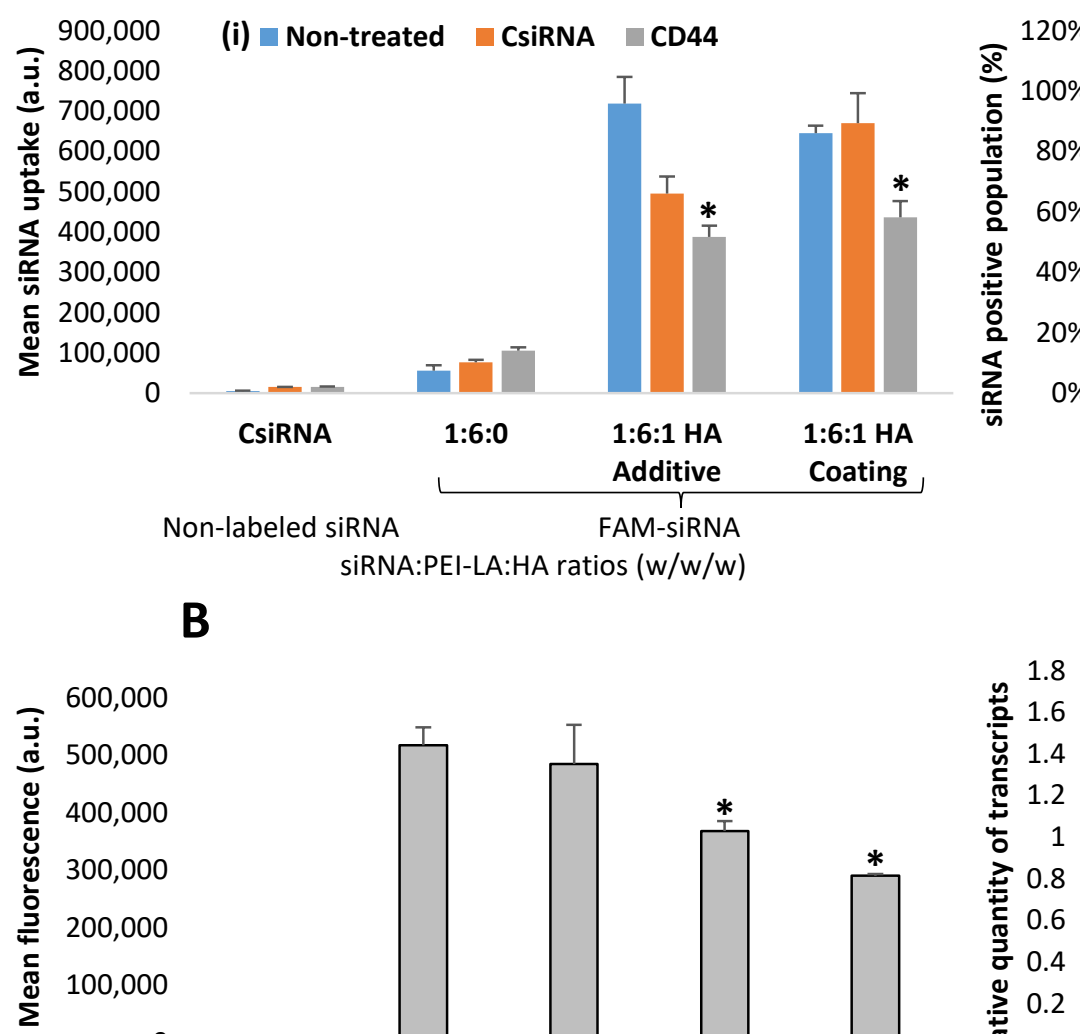

600,000
500,000
400,000
300,000
200,000
100,000
0
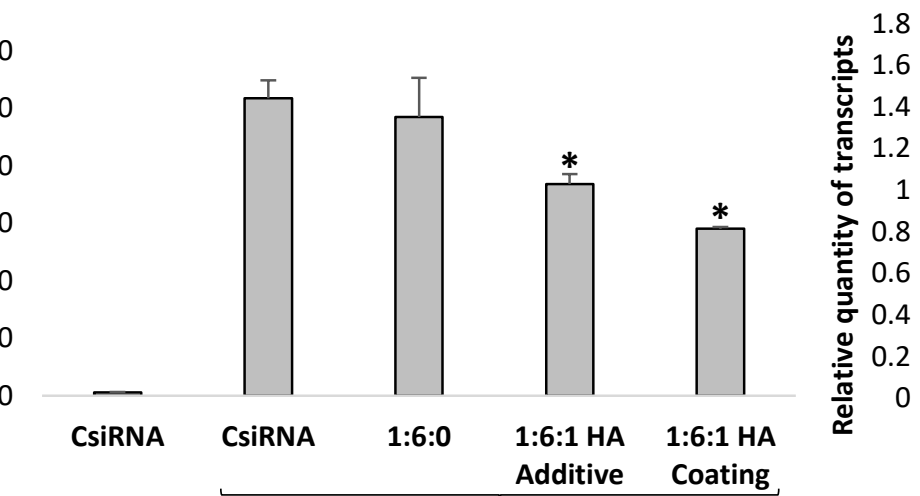

Control IgG

CD44 Antibody siRNA:PEI-LA:HA ratios (w:w:w)

1:6:0

CsiRnA

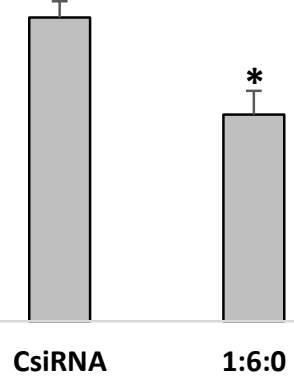

(ii) Non-treated CsiRNA $\square$ CD44

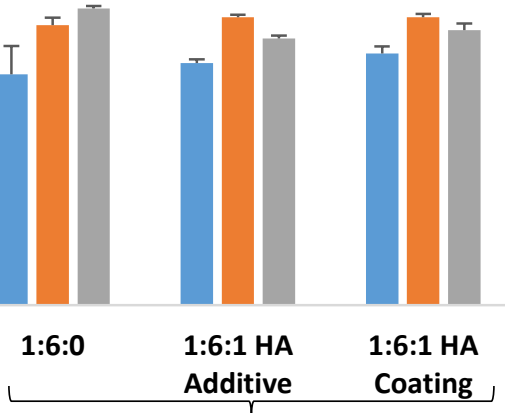

FAM-siRNA

SiRNA:PEI-LA:HA ratios (w/w/w)

\section{C}

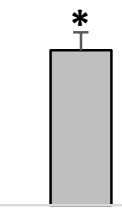

1:6:1 HA Additive

1:6:1 HA Coating

SiRNA:PEI-LA:HA ratios (w/w/w) 


\section{Figure 5}
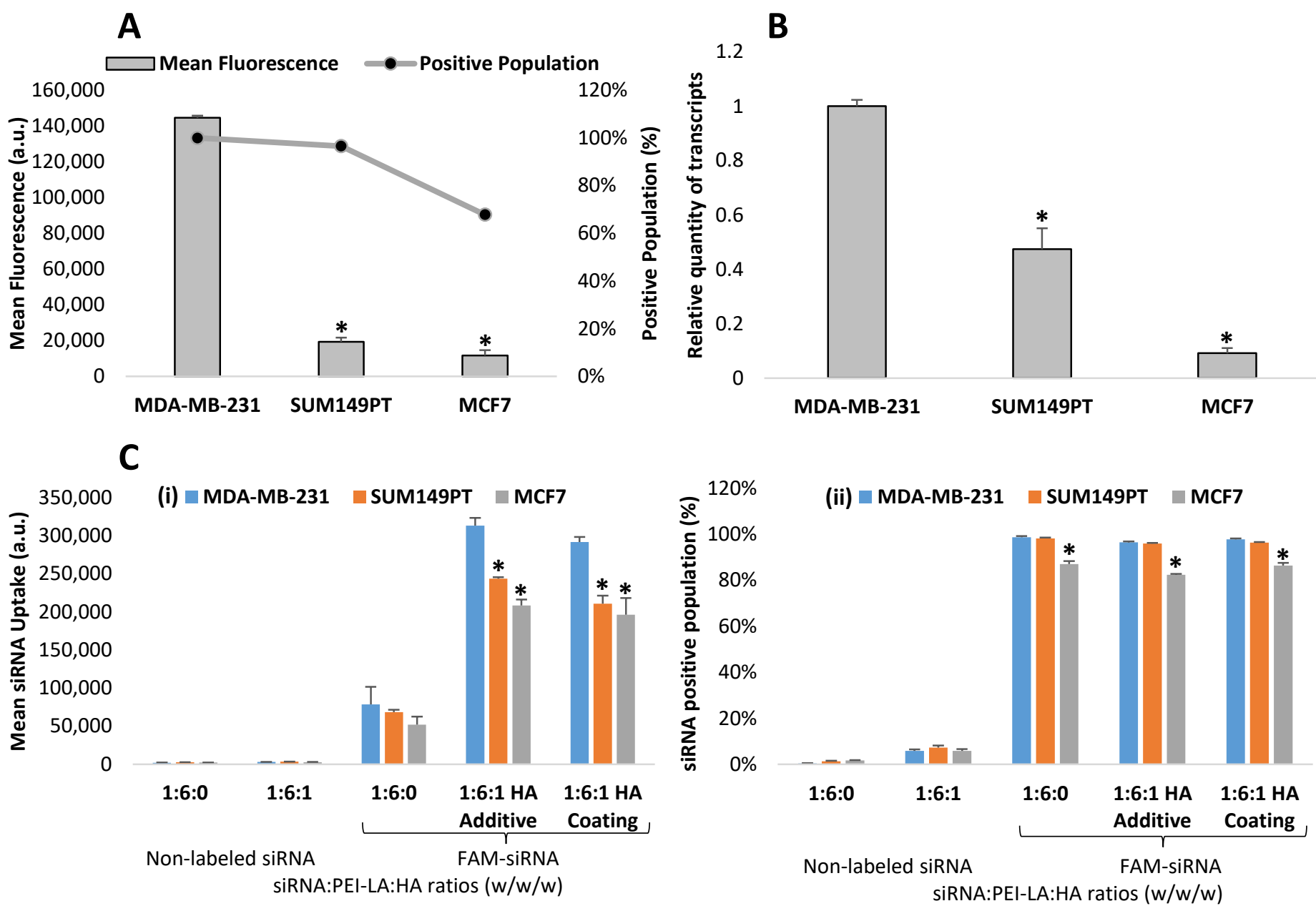
Figure 6
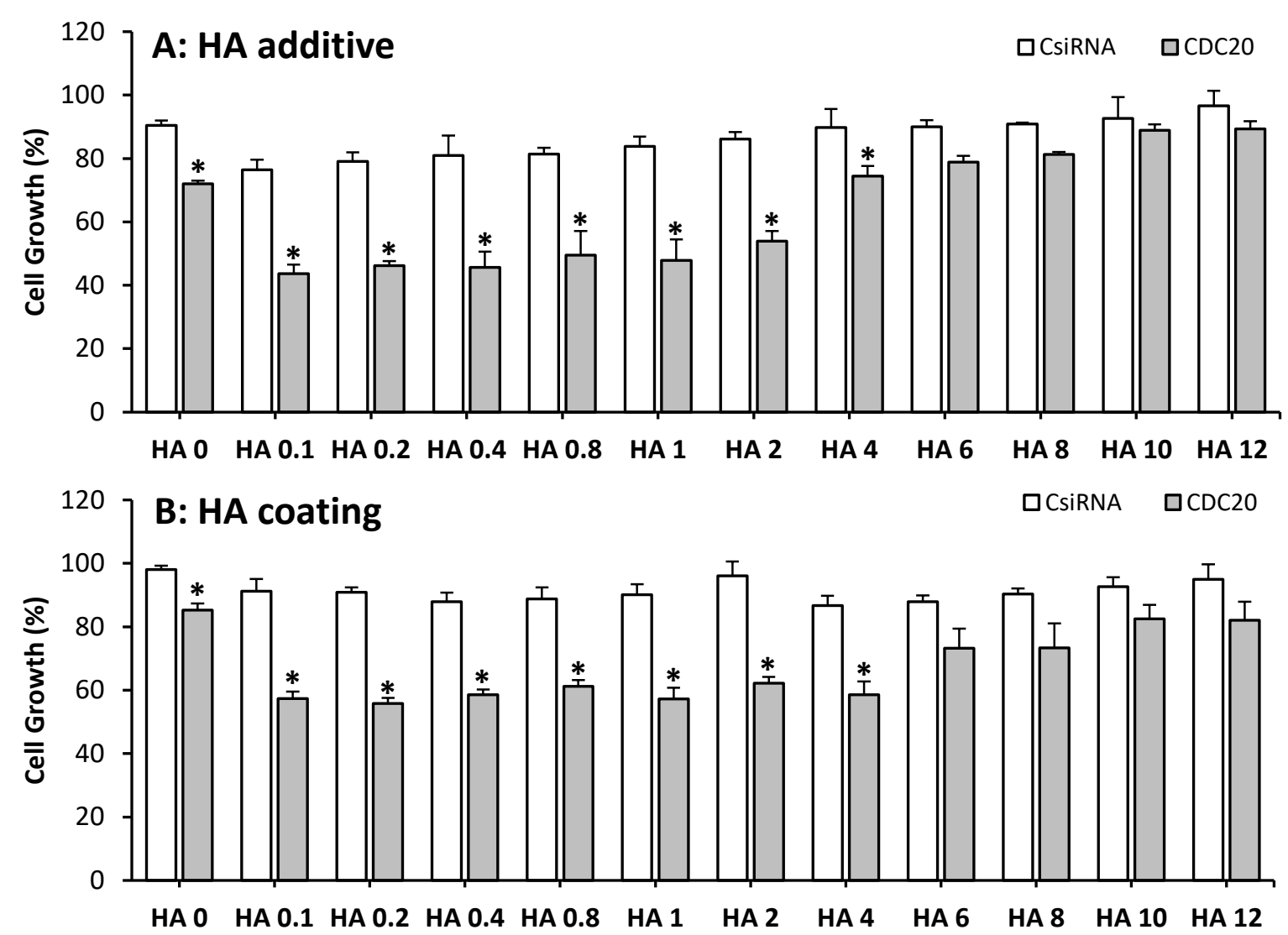
Figure 8

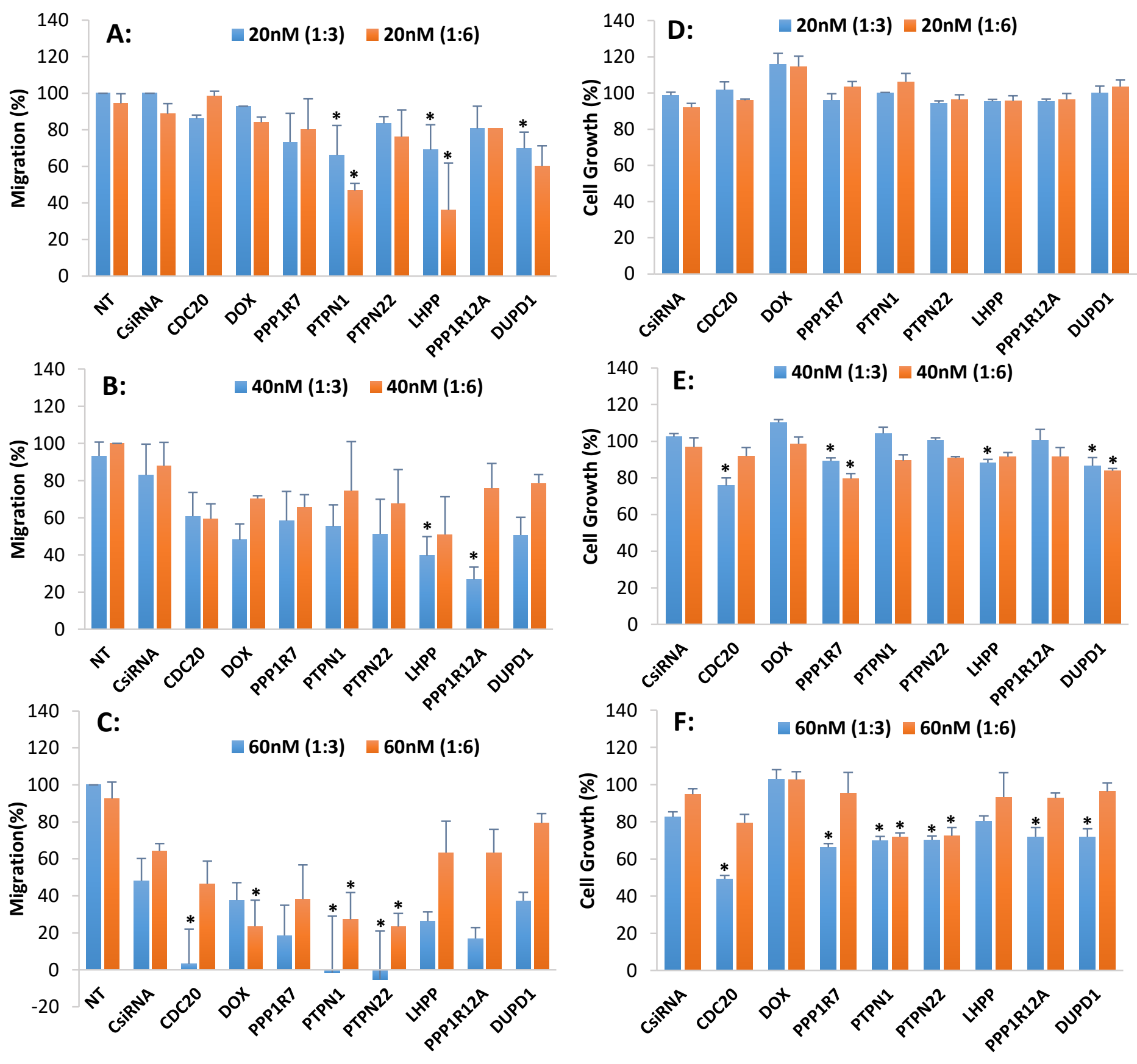




\section{ACCEPTED MANUSCRIPT}
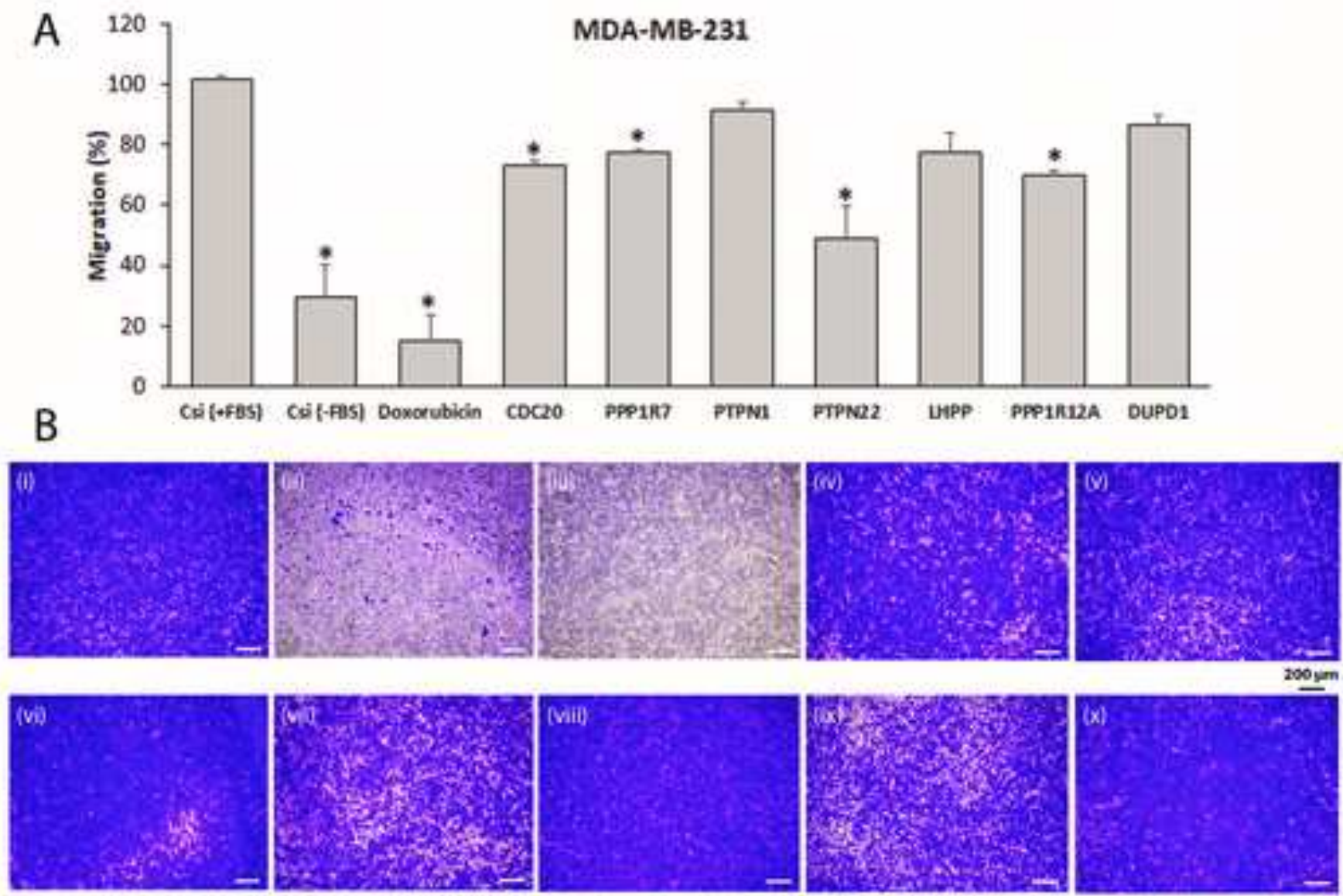
Figure 10

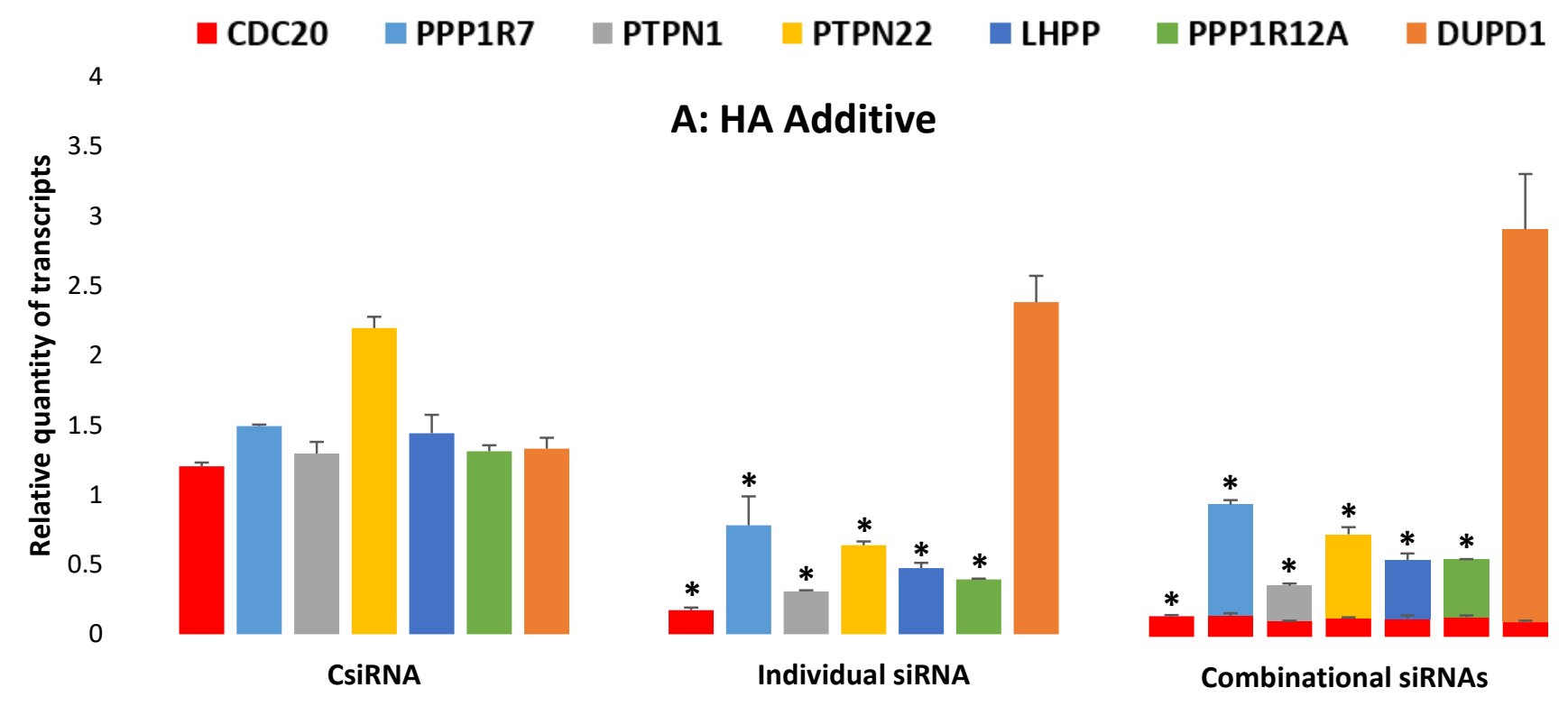

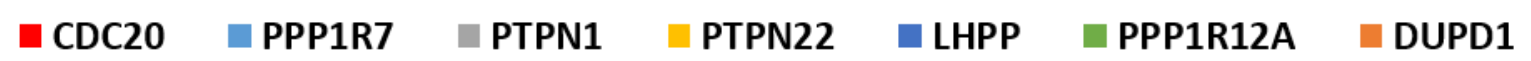

4

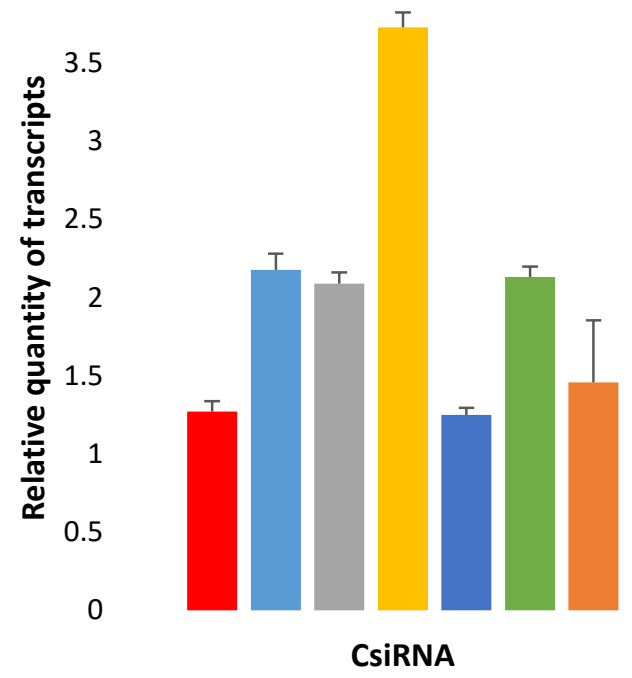

B: HA Coating

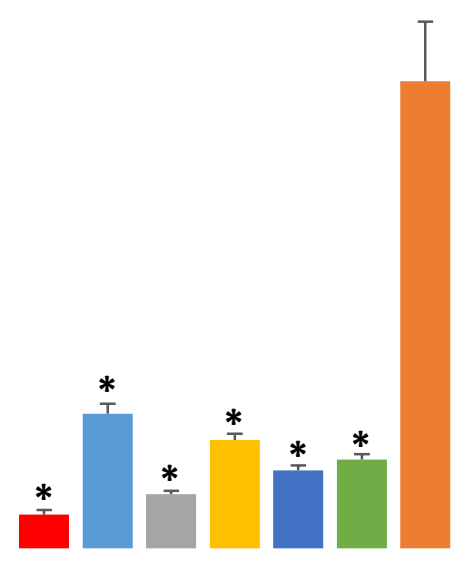

Individual siRNA

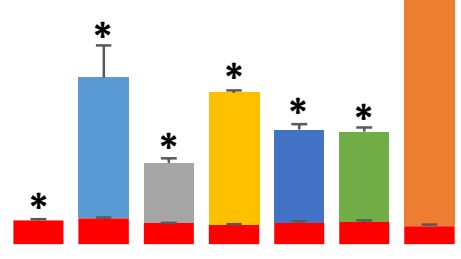

Combinational siRNAs 
Figure 11

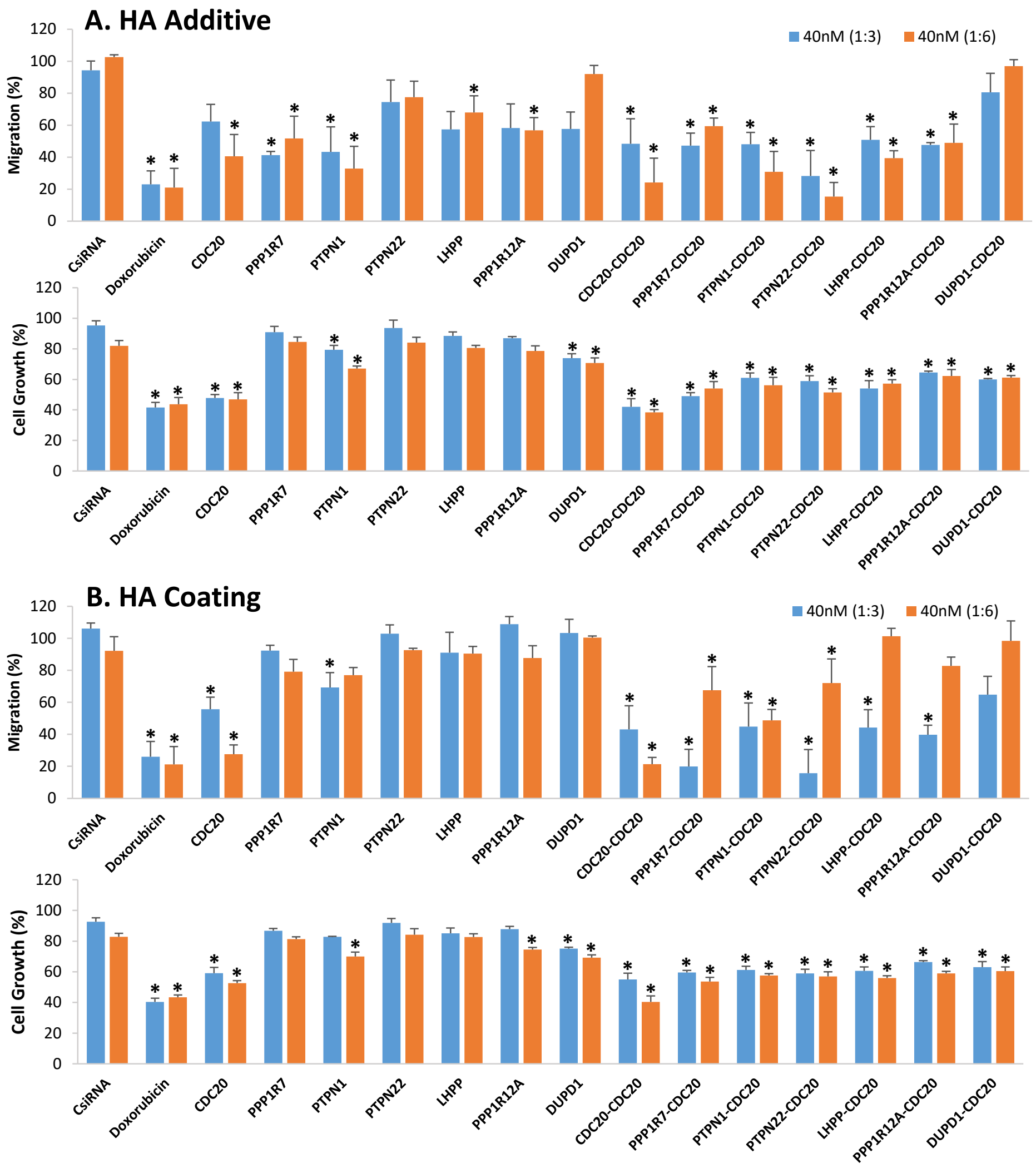




\section{Graphical Abstract}

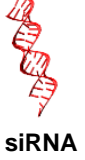

$+$

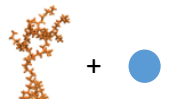

PEI-LA HA

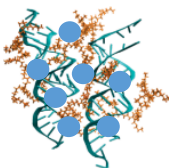

Complexes

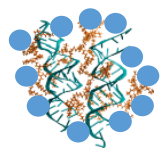

Inhibition of Cell Growth and Migration

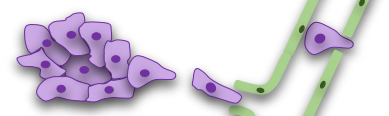




\section{Statement of Significance:}

The manuscript investigated the efficacy of a tailored polymeric siRNA delivery system formulation as well as combinational siRNA therapy in metastatic breast cancer cells to inhibit malignant cell growth and migration. The siRNA delivery was undertaken by non-viral means with PEI/HA. We identified six phosphatases that could be critical targets to inhibit migration of highly aggressive metastatic breast cancer cells. We further report on specifically targeting cell cycle and phosphatase proteins to decrease both malignant cell growth and migration simultaneously. Clinical gene therapy against metastatic breast cancer with effective and safe delivery systems is urgently needed to realize the potential of molecular medicine in this deadly disease and our studies in this manuscript is intended to facilitate this endeavor. 